\title{
Neue Grabinschriften aus Neoklaudiopolis (Vezirköprü/Samsun İli, Türkei)
}

\author{
Vera SAUER* - Eckart OLSHAUSEN** \\ In herzlichem Gedenken an einen lieben Kollegen - Sencer Şahin
}

Bislang waren ungefähr 140 Grabinschriften bekannt, die aus dem Territorium von Neoklaudiopolis stammen. ${ }^{1}$ Im folgenden seien 14 weitere vorgestellt, von denen eine allerdings möglicherweise Amaseia zuzuordnen ist (Nr. 4). Die Inschriften wurden in den Jahren 1988 bis 1990 von Eckart Olshausen und Gerhard Kahl aufgenommen. ${ }^{2}$

\section{Nr. 1 Für Usia Eutychis}

Ilıca/Havza (10,4km nordnordöstl. Havza; 21,6km ostsüdöstl. Vezirköprü). Aufgestellt im Hof des Bekir Altun. 1989 (Photos, Abklatsch, Skizze der Stele, Abschrift). 2013 liegend wiedergesehen (UTM: 36T 726420/4548753). ${ }^{3}$

Giebelstele. Kalkstein. Unterhalb des Giebels ein Bildfeld. Giebel-, Bild- und Schriftfeld vertieft, durch Stege voneinander getrennt. Der Steg zwischen Bild- und Schriftfeld ist mit einer Rille versehen. Im Giebelfeld Rosette. Akrotere mit stilisierten, nach außen geschwungenen Blättern. Im Bildfeld Korb, Spiegel und Kamm. Im Schriftfeld unten mittig ein relativ großes (Efeu-)Blatt an kurzer Ranke (graviert). Die Kanten des Giebels und die Akrotere sind bestoßen, die linke untere Ecke des Schriftfelds ist abgebrochen.

H 124cm; B $48 \mathrm{~cm}$; T $37 \mathrm{~cm}$. Schriftfeld: H $65 \mathrm{~cm}$; B 39cm. Bh. 1,8-4,0 cm; besonders auffallend ist die Variationsbreite der Bh. bei Omikron und Sigma.

In Z. 1, 2 und 4 berührt der letzte Buchstabe den Rahmen des Schriftfelds. Alpha: Querstrich waagerecht. Epsilon: lunar. My: eckig mit schräg stehenden Hasten. Pi: Deckstrich ragt über die

* Dr. Vera Sauer, Mühlweg 6, D-72414 Rangendingen, Deutschland (vera.sauer@gmx.de; (D) https:// orcid.org/0000-0001-7283-6390).

** Prof. Dr. Eckart Olshausen (Prof. em. Universität Stuttgart), Mühlweg 6, D-72414 Rangendingen, Deutschland (eckart.olshausen@gmx.de; (D) https://orcid.org/0000-0001-6565-4951).

Wir danken Tønnes Bekker-Nielsen, Wolfgang Blümel, Elisabeth Herrmann-Otto, Christian Marek, Georg Petzl, Søren Lund Sørensen, Kristina Winther-Jacobsen und dem/der anonymen Gutachter/-in herzlich für ihre anregenden Hinweise.

${ }^{1}$ Vgl. Studia Pontica III; Olshausen - Biller 1984, 83f., Abb. 21; Olshausen 1987 (mit Sauer - Olshausen 2018, 125 mit Anm. 4 und 5); Marek 2000, 137-146 Nr. III; Bekker-Nielsen - Høgel 2012; Sørensen 2013; Bekker-Nielsen - Høgel - Sørensen 2015; Marek - Adak 2016; Sauer - Olshausen 2018; 2019; 2020; 2021.

${ }^{2}$ Alle sind kaiserzeitlich. Zu den Surveys, in deren Rahmen sie dokumentiert wurden, vgl. Olshausen 1990 und auch Kahl - Olshausen 1991. Bei der Lagebeschreibung der Fundorte sind die Distanzangaben im Sinn von `ca. ... km Luftlinie` zu verstehen.

${ }^{3}$ Im Rahmen eines Surveys des an der Süddänischen Universität angesiedelten Projekts »Where East meets West $\lll$. 
Hasten hinaus. Sigma: lunar. Ypsilon: Arme teils leicht geschwungen; in Z. 2 ist das erste Ypsilon annähernd V-förmig. Delta, teils auch Alpha mit Apices.

In Z. 1 berühren sich Sigma und Tau, in Z. 2 Ypsilon und Chi, in Z. 3 Gamma und Ypsilon.

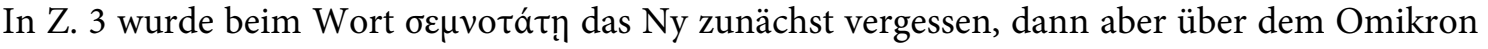
im Zeilenzwischenraum ergänzt.

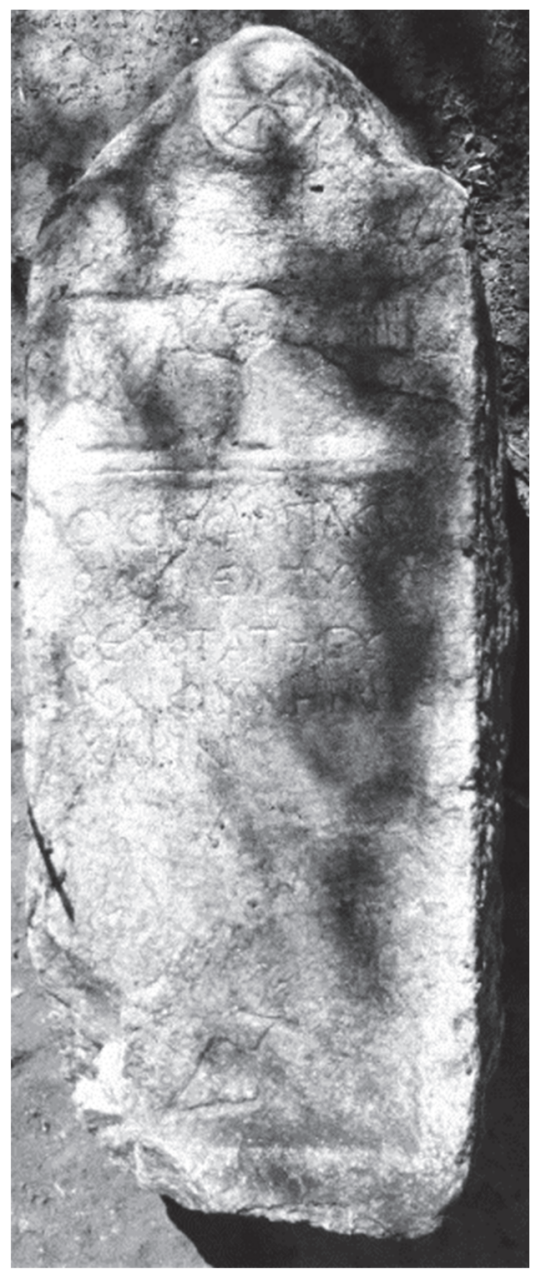

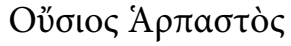

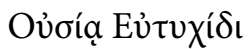

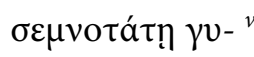 \\ vaıkì $\mu v \eta \dot{\mu \eta} \varsigma$

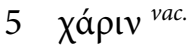 \\ vacat - 4 Zeilen -
}

vac. hedera vac.

Usius Harpastos der Usia Eutychis, der ehrwürdigsten Frau, des Gedenkens wegen.

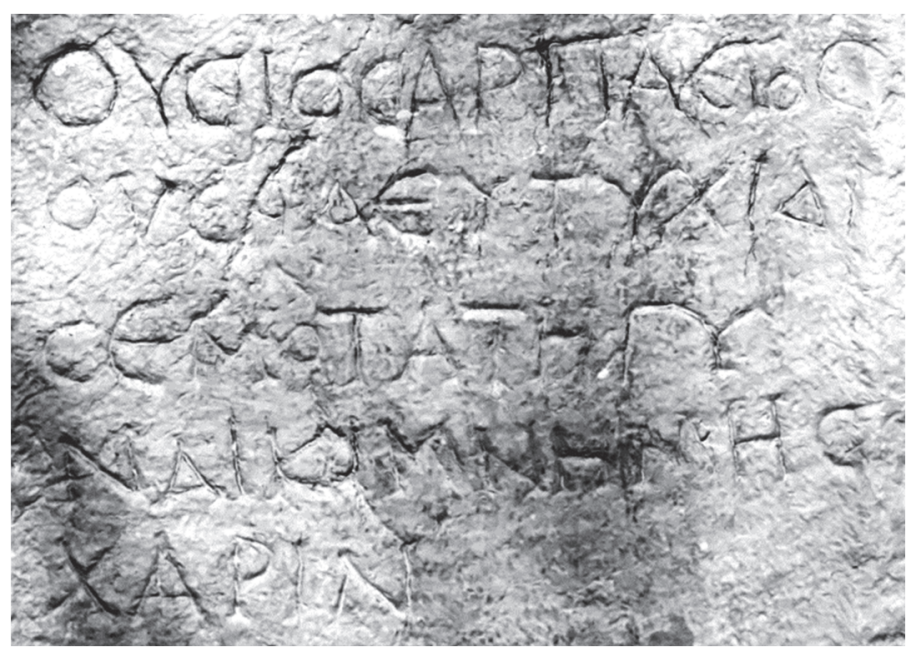

Abb. 1-2) Nr. 1 Für Usia Eutychis (2013 bzw. 1989)

In lateinischen, überwiegend aus Italien stammenden Inschriften ist das nomen gentile Usius gut bezeugt. ${ }^{4}$ In der hier vorliegenden Inschrift und unten in Nr. 2 begegnet es nun, soweit wir sehen, erstmals in griechischen Inschriften. ${ }^{5}$

${ }^{4}$ Vgl. Schulze 1904, 261f. (mit Solin - Salomies 1994, s.v.).

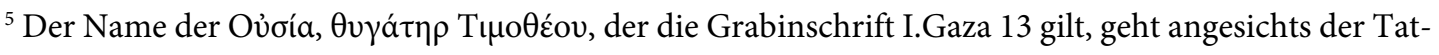
sache, daß diese Inschrift sich relativ spät datiert (563 n.Chr.), wohl kaum auf das insgesamt gesehen doch sehr seltene lateinische nomen zurück; er dürfte vielmehr mit dem griechischen Begriff oủoía in Zusammenhang stehen. 


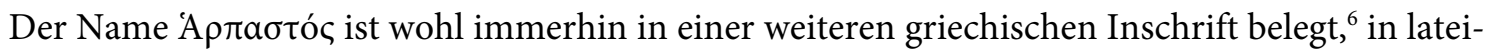
nischen Inschriften etwas häufiger. ${ }^{7}$ Möglicherweise spiegelt er das Schicksal seines Trägers (>der Geraubte/der Gefangene`).

Daß Harpastos und seine Frau dasselbe nomen gentile tragen, kann etwa damit zu erklären sein, daß sie miteinander verwandt waren oder Eutychis Freigelassene ihres Mannes gewesen ist. Denkbar ist insbesondere aber auch, daß beide (oder ihre Vorfahren) ihr Bürgerrecht ein und derselben Person verdankten - vielleicht gar jener, auf die auch das Bürgerrecht der in Nr. 2 genannten Usia Zoë und des Usius Eleutheros zurückgeht. Dies ist umso wahrscheinlicher, als beide Stelen ähnlich gestaltet und ihre Fundorte nur ca. $5,5 \mathrm{~km}$ voneinander entfernt sind. ${ }^{8}$ Harpastos und Eutychis, Zoë und Eleutheros mögen auf den oder jedenfalls in der Nähe der Besitzungen ihres Patrons gelebt und ihre Grabsteine aus derselben Werkstatt bezogen haben.

\section{Nr. 2 Für Usia Zoë}

Arslançayırı/Havza (5,5km nördl. Havza; 21,8 km südöstl. Vezirköprü). Im Hof des Hasan Delibaş. Soll 1985 beim Bau eines Brunnens zum Vorschein gekommen sein. 1989 (Photos, Abklatsch, Skizze der Stele, Abschrift).

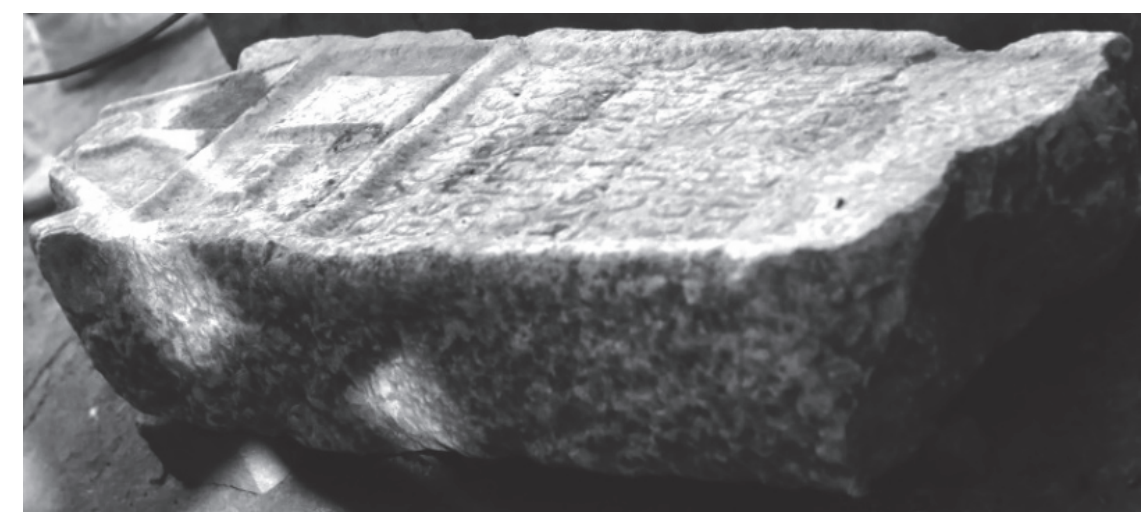

Abb. 3) Nr. 2 Für Usia Zö̈

Giebelstele. Kalkstein. Unterhalb des Giebels ein Bildfeld. Giebel-, Bild- und Schriftfeld vertieft, durch Stege voneinander getrennt. Im Giebelfeld Spiegel. Im Bildfeld Kamm und Korb. Akrotere

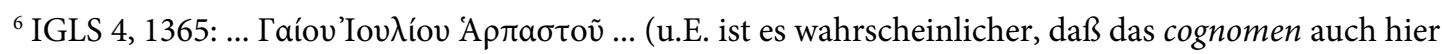

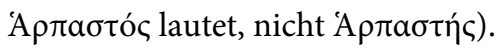

${ }^{7}$ Vgl. etwa CIL 8, 21909; LMentana 152 = AE 1985, 141; I.Aquileia 1, 624.

${ }^{8}$ Vgl. insbesondere das zwischen Giebel und Schriftfeld platzierte und vom Schriftfeld durch einen Steg getrennte Bildfeld. In dieser Weise gegliederte Stelen sind im Territorium von Neoklaudiopolis recht selten: Bislang sind lediglich drei weitere bekannt. Deren Fundorte konzentrieren sich nördlich von Havza und sind von Ilıca nicht weiter entfernt als Arslançayırı, der Fundort der Stele mit Inschrift Nr. 2: Olshausen 1987, 87f. Nr. 5 = SEG 37, 1089 (vom Samsun Arkeoloji ve Etnografya Müzesi in Sivrikese Köyü aufgekauft, also sicherlich in der Nähe dieses Ortes gefunden; zu Provenienz und Datierung vgl. Sauer - Olshausen 2018, 125 mit Anm. 4 und 5); Studia Pontica III 41 (Fundort Eski viran - 2,2 km westl. Sivrikese, vgl. Türkeikarte 1:200.000, Blatt B IX Samsun, Harita Genel Müdürlüğü Ankara 1947 -, von Eckart Olshausen und Gerhard Kahl 1989 in Sivrikese wiedergesehen); Studia Pontica III 61a (Fundort Kocaoğlu); zur Frage, was im Bildfeld dieser drei Stelen dargestellt ist, vgl. Sauer - Olshausen 2020, 155f. Anm. 55.
} 
mit stilisierten, nach außen geschwungenen Blättern. Giebelspitze und unterer Abschluß des Schriftfelds abgebrochen, Rahmen des Bild- und des Schriftfelds rechts leicht bestoßen.

H $118 \mathrm{~cm}$; B 38cm; T 23cm. Schriftfeld: H $65 \mathrm{~cm}$ erhalten; B $32 \mathrm{~cm}$. Bh. 3,5-4,0 cm.

Fast alle Buchstaben schmal und hoch, insbesondere Epsilon und Sigma. Alpha: Querstrich waagrecht. Epsilon: lunar. My: kursiv. Ny: in Z. 7 berührt die Diagonale die zweite Haste nicht. Sigma: lunar. Ypsilon: Arme unterschiedlich lang (vgl. besonders Z. 1, zweiter Buchstabe: annähernd Vförmig, letzter Buchstabe: Arme sehr kurz), dabei leicht geschwungen. Phi: Haste lang. Omega: $\omega$-förmig. Lambda mit Apex.

In Z. 6 ist das Delta durch Leerstellen, die das Zeichen flankieren, als Ziffer kenntlich gemacht. Zudem unterscheidet sich das Zahlzeichen vom Buchstaben Delta (in Z. 3) dadurch, daß die Grundlinie links und rechts über den Auf- bzw. Abstrich hinaus verlängert ist.
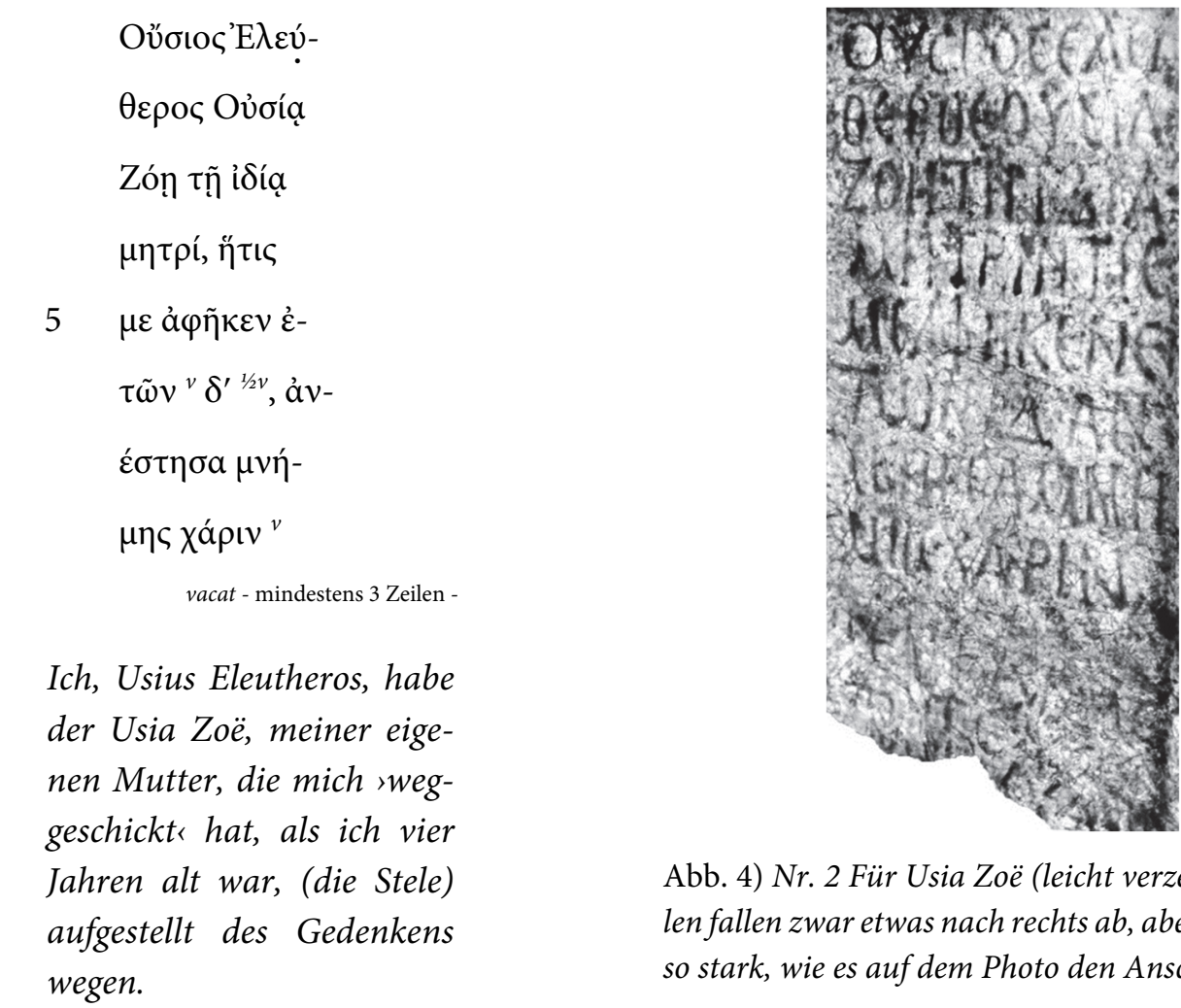

Abb. 4) Nr. 2 Für Usia Zoë (leicht verzerrt: die Zeilen fallen zwar etwas nach rechts ab, aber nicht ganz so stark, wie es auf dem Photo den Anschein hat)

Deutlich beschriftet sind nur die oberen $46 \mathrm{~cm}$ des Schriftfelds (Z. 1-8). Aber auch unterhalb von Z. 8 sind schemenhaft Spuren von Buchstaben zu erkennen. Da jedoch die Oberfläche des Steins auch in diesem Bereich nicht beschädigt ist, ist der unterschiedliche Erhaltungszustand wohl am ehesten damit zu erklären, daß die schemenhaften Reste von einer früheren Inschrift herrühren. Die Oberfläche des Schriftfelds dürfte ziemlich genau in Buchstabentiefe abgetragen, geglättet und dann neu beschriftet worden sein.

Z. 1-2’E $\lambda \varepsilon v \underline{\mid} \mid \theta \varepsilon \rho \circ$ c $_{\text {: }}$ Die Arme des Ypsilon sind so kurz, daß es kaum von Iota unterscheidbar ist.

Z. $5 \mu \varepsilon$ ả $\varphi \tilde{\eta} \kappa \varepsilon v:$ Im Abklatsch und auf den Photos zeichnen sich bei beiden Epsilon die Arme, bei Alpha und Eta die Querstriche nicht ab; am Stein waren die Buchstaben aber vollständig erkennbar. 
Z. 3 Zón für Zún, wie häufig in der Koine. ${ }^{9}$

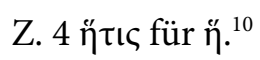

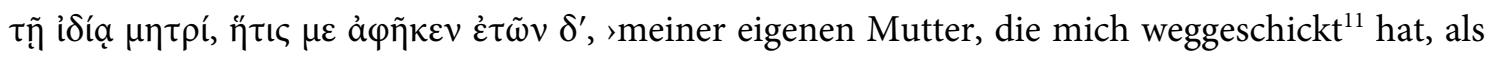

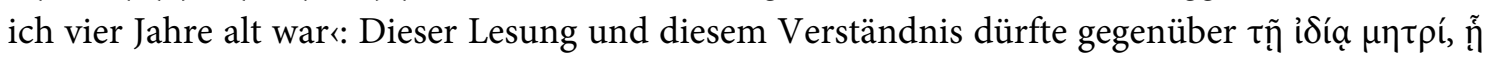
$\tau i ́ \varsigma \mu \varepsilon \dot{\alpha} \varphi \tilde{\eta} \kappa \varepsilon v \dot{\varepsilon} \tau \tilde{\omega} v \delta^{\prime}$, > meiner eigenen Mutter, der mich einer im Alter von vier Jahren überlassen hat $\triangleleft$ der Vorzug zu geben sein.

Vorzustellen hat man sich wohl, daß Zoë ihren Sohn in eine Pflegefamilie gegeben hat, in der er dann als $\theta \rho \varepsilon \pi \tau$ ć aufgewachsen ist, wobei er den Kontakt zu seiner leiblichen Mutter offenkundig aber nicht gänzlich verlor. ${ }^{12}$ Die Namensgleichheit von Mutter und Sohn kann etwa damit zu erklären sein, daß der Sohn sein römisches Bürgerrecht zunächst alleine dem Status seiner Mutter, nicht dem seines Vaters verdankte und dann von seinen Pflegeeltern nicht als Sklave, sondern als Freier aufgezogen wurde. Denkbar ist, daß sein cognomen Eleutheros diese Tatsache unterstreichen sollte, denkbar ist aber auch, daß er es schon vor der Aufnahme in die Pflegefamilie erhalten hatte, etwa, falls seine Mutter, vielleicht auch er selbst, Freigelassene gewesen sein sollte.

So stimmig diese Lesung und das vorgeschlagene Szenario im Prinzip wohl sind, über alle Zweifel

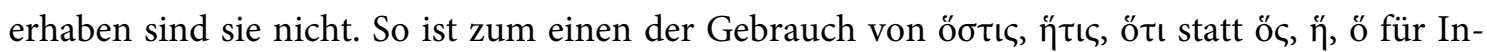
schriften aus Neoklaudiopolis, soweit wir sehen, bislang nicht belegt. ${ }^{13}$ Zum anderen - und dies

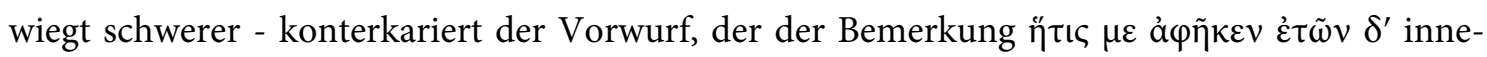

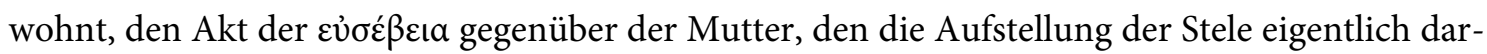
stellt und gleichzeitig dank der Inschrift dokumentiert. Daher sei, gleichsam in Parenthese, ein Szenario zur Diskussion gestellt, das die Vorgänge, die die Inschrift spiegelt, erklären könnte,

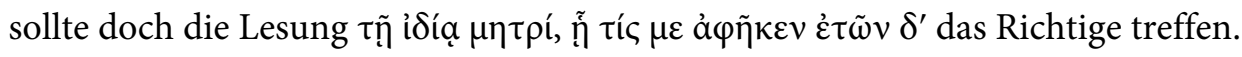

Diesem Szenario zufolge, wäre die Mutter eine Freigelassene; sie trägt das nomen gentile ihres ehemaligen Besitzers. Ihren Sohn hatte sie noch vor ihrer Freilassung geboren; so verblieb er im Besitz ihres ehemaligen Herrn. Dieser >überließ den Knaben aber der Mutter, etwa indem er ihn ihr schenkte oder verkaufte. Schließlich ließ die Mutter ihren Sohn frei. Dadurch wurde sie seine patrona, und er trug nun ihr nomen gentile, das freilich mit dem seines ehemaligen Herrn identisch ist. ${ }^{14}$ Das cognomen Eleutheros dokumentiert gleichsam seinen neuen Status. - In der Notiz

\footnotetext{
${ }^{9}$ Zur Vertauschung von Omikron und Omega in Folge des Schwindens der Unterscheidung der Vokalquantitäten vgl. Schwyzer 1939, 129, 392f.; Gignac 1976, 275-277, 325.

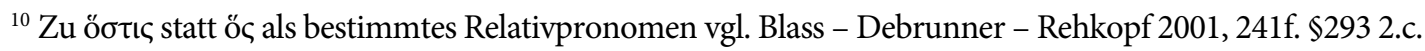

${ }^{11} \mathrm{Ob}$ ả $\varphi$ เ́vaı hier eher im Sinn von >verlassen/alleine lassen ‘ als im Sinn von `wegschicken` zu verstehen ist, sei dahingestellt. Daß damit gegebenenfalls `meiner Mutter, die gestorben ist, als ich vier Jahre alt war gesagt sein sollte, kann man wohl ausschließen, da man sonst entweder verstehen müßte, der Sohn habe die Stele als Vierjähriger oder aber Jahre nach dem Tod der Mutter aufgestellt.

${ }^{12} \mathrm{Zu}$ alumni bzw. $\theta \rho \varepsilon \pi \tau o$, ‘Zöglingen`, vgl. etwa Herrmann-Otto 2012, passim; speziell für Kleinasien zusammenfassend Bekker-Nielsen - Høgel 2012, 156 (mit Literatur).

${ }^{13}$ Vgl. außerdem Brixhe 2010, 241, der für Kleinasien feststellt »őৎ, ฑ̋, ő remain the norm«.

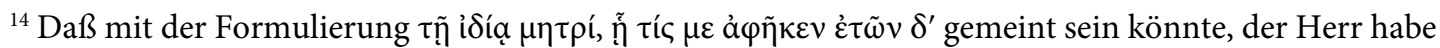

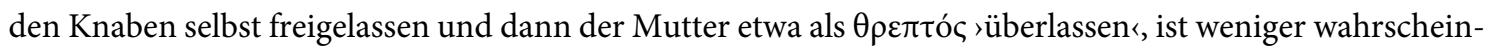
lich - jedenfalls, wenn man davon ausgeht, die Freilassung sei strikt am Römischen Recht orientiert vonstatten gegangen. Entsprechend den Regelungen der Lex Aelia Sentia konnten Personen vor ihrem 30. Le-
} 


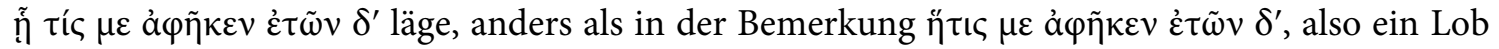
der Verstorbenen, erinnert sie doch an das Verdienst der Mutter, die Freiheit des Sohnes bewirkt zu haben. Schwer erklärbar wäre freilich, weshalb der Sohn dieses Lob derart kryptisch formuliert haben sollte.

Zum nomen gentile Usius vgl. oben Nr. 1; vgl. Nr. 1 auch zu denkbaren Gemeinsamkeiten der dort und der hier genannten Personen.



Abb. 5) Nr. 3 Für Dometianus

\section{Nr. 3 Für Dometianus}

Doyran/Vezirköprü (2,7km südsüdöstl. Vezirköprü). In der Umfassungsmauer der cami vermauert. 1988 (Photos, Skizze des Stele, Abschrift).

Fragment einer Giebelstele. Kalkstein. Giebel- und Schriftfeld vertieft, jeweils von profiliertem Rahmen umgeben. Im Giebelfeld auffallend plastisch herausgearbeiteter Pinienzapfen. Linker Akroter bestoßen. Unten und im Bereich der Z. 5-9 rechts gebrochen. Bruchkanten unter Mörtel verborgen.

H $71 \mathrm{~cm}$; B oben $43 \mathrm{~cm}$. Schriftfeld: H $29 \mathrm{~cm}$ erhalten; Breite oben $28 \mathrm{~cm}$. Bh. $2,3 \mathrm{~cm}$.

Alpha: Querstrich waagrecht. Epsilon: eckig. My: eckig mit parallel stehenden Hasten. Sigma: eckig. ${ }^{15}$ Omega: $\Omega$-förmig, wobei der Bogen des $>$ Hufeisens $`$ nicht nach innen eingezogen ist. Lambda teils mit Apex. Teils leichter Ansatz zu Serifen.

bensjahr nämlich nur dann vollgültig freigelassen werden, wenn zwischen ihnen und dem Freilassenden ein besonderes Naheverhältnis bestand. Im vorliegenden Fall dürfte diese Voraussetzung erfüllt gewesen sein; anderenfalls hätte Eleutheros durch die Angabe, in welchem Alter er `überlassen` worden war, den Mangel, der seinem Status anhaftete, geradezu betont. Ein Naheverhältnis, das die >vorzeitige` Freilassung ermöglichte, war cognatio naturalis, weswegen eine Mutter ihren Sohn fraglos vollgültig freilassen konnte. Sollte dieser filius naturalis seines Herrn gewesen sein, hätte auch jener ihn aus demselben Grund vollgültig freilassen können. Die auffallend unbestimmte Art, in der von demjenigen die Rede ist, der den Knaben seiner Mutter >überlassen` hat ( $\tau \iota \varsigma)$, könnte man geradezu als Indiz dafür werten, daß einerseits tatsächlich eine derartige cognatio naturalis bestanden hat, diese andererseits jedoch nicht zur Legitimation der Freilassung herangezogen wurde, respektive die Freilassung nicht durch den pater naturalis erfolgte. Vorstellbar wäre, daß die Vagheit der Formulierung ebenso wie seinerzeit der Vorgang des >Überlassens` des Knaben dem Bemühen geschuldet war, die Vaterschaft seines einstigen Besitzers zu verschleiern - eine Möglichkeit, auf die uns dankenswerterweise Elisabeth Herrmann-Otto aufmerksam gemacht hat; vgl. zu diesem Phänomen Herrmann-Otto 1994, 44, 87, 163, 228. Zu den erwähnten Bestimmungen der Lex Aelia Sentia vgl. Dig. 40,2,13; Inst. Iust. 1,6,5f.; Gai. inst. 1,19; dazu etwa Herrmann-Otto 1994, passim, bes. 255, 288; 2012, passim, bes. 175-177, 189; 2017, $233 \mathrm{f}$.

${ }^{15}$ Eckig meint hier und im folgenden, daß das Sigma von einer Haste und zwei waagrechten Armen gebildet wird. 


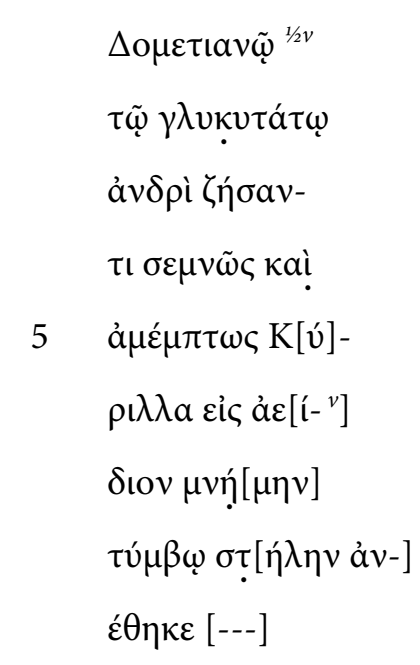

Dem Dometianus, dem süßesten Mann, der ehrwürdig und tadellos gelebt hat, hat Kyrilla zu immerwährendem Gedenken auf dem Grab die Stele aufgestellt ...

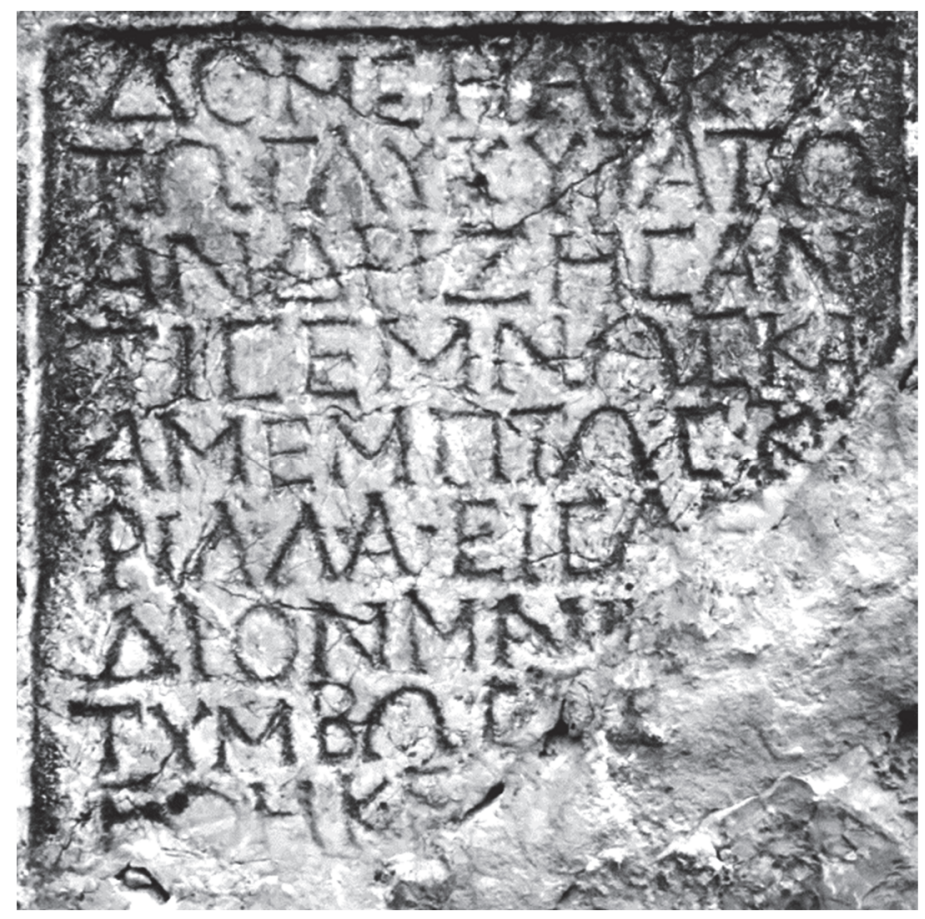

Abb. 6) Nr. 3 Für Dometianus

Z. $2 \gamma \lambda \nu \kappa v \tau \alpha ́ \tau \omega ̣:$ Kappa annähernd sicher.

Z. 4 кá:: Vom Iota ist nur der obere Ansatz erhalten.

Z. $7 \mu v \underline{\text { f }}[\mu \eta \nu]$ : Vom Eta ist nur der obere Ansatz der ersten Haste erhalten.

Z. $8 \sigma \tau\left[\eta \lambda_{\eta \eta} \vee \alpha ̉ v-\right]:$ Tau annähernd sicher. Sigma und Tau schmal; vorausgesetzt, auch die folgenden Buchstaben waren so gestaltet oder gar durch Ligatur verbunden, war auch für die Vorsilbe àv - Platz.

\section{Nr. 4 Für eine früh verstorbene Person}

Eynekaraca/Ladik (8,1km westl. Ladik; 37,7km südöstl. Vezirköprü). Im Stall des Turgut Ergen vermauert. Soll aus Cevizlik Mevkii stammen, womit wohl eher eine lokale Örtlichkeit als Cevizlik Köyü/Havza (ehem. Hurdaz; 13,6km nordnordwestl. Eynekaraca) gemeint ist. 1989 (Photos, Abklatsch, Skizze des Fragments, das die Inschrift trägt, Abschrift).

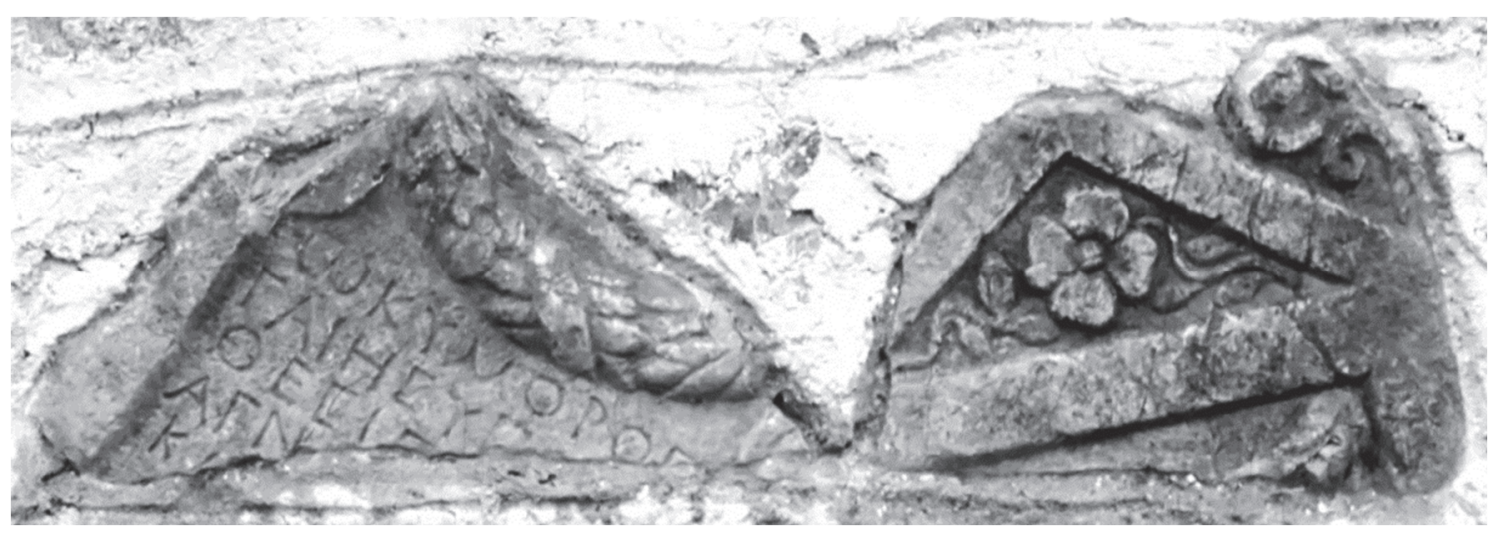

Abb. 7) Nr. 4 Für eine früh verstorbene Person 
Zwei Fragmente einer Giebelstele. Kalkstein. Giebel- und Schriftfeld vertieft. Im Giebelfeld Ranke mit Blüte (zentral) und drei Blättern (rechts) und eine zweite Ranke (links) mit zwei Blättern und wohl einer Knospe (nach oben zeigend). Akroter mit nach innen gerollten stilisierten Blättern. Im Schriftfeld über der Inschrift Girlande aus Blättern mit einer Blüte (links), von einem Band umwunden, dessen Enden links (hier besser erkennbar) und rechts bogenförmig herabhängen. Bis-

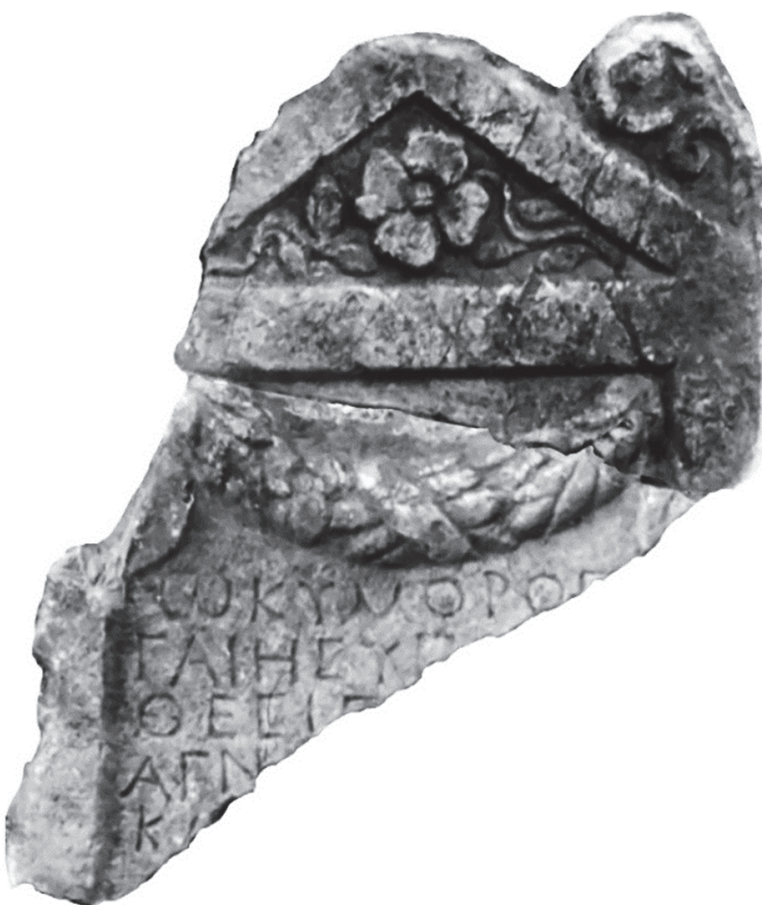

Abb. 8) Photomontage aus Abb. 7 lang ist dies die einzige Grabstele mit Girlandendarstellung, die aus dem Territorium von Neoklaudiopolis bekannt ist. ${ }^{16}$ Die beiden Fragmente schließen direkt aneinander an; der Bruch trennt, leicht nach rechts abfallend, den Giebel mit dem rechten Ansatzpunkt der Girlande vom Schriftfeld. Die linke Ecke des Giebels, der linke Akroter und die untere Partie der Stele fehlen; die untere Bruchkante verläuft nach rechts aufsteigend durch das Schriftfeld.

Schriftfeld: B $28,5 \mathrm{~cm}$ erhalten (gemessen am oberen Abschluß der 1. Zeile). Bh. 2,2$2,8 \mathrm{~cm}$.

Alpha: Querstrich waagrecht. Epsilon: eckig. My: kursiv. Sigma: eckig. Ypsilon: Arme geschwungen. Omega: $\omega$-förmig.

${ }^{1 / 2 v} \dot{\omega} \kappa u ́ \mu о \rho о \varsigma, ~\left[{ }^{v}\right]$

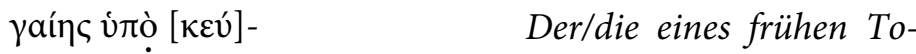

$\theta \varepsilon ́ \sigma ı$ ?--- $]$

$\mathrm{A} \Gamma \mathrm{N}[---]$ des sterbende ... unten, in den verborgenen Tiefen

$5 \quad \mathrm{~K} ?[---]$ der Erde ...

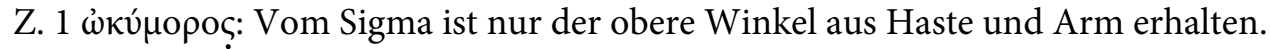

Z. 2 ưró: Vom Omikron ist lediglich ein Teil des oberen Bogens erhalten.

Z. 3 Auf Iota folgt eine Haste, an die oben eher ein Arm als eine Deckstrich ansetzt.

Z. 5 Auf Kappa folgt ein mit Aufstrich beginnender Buchstabe.

Z. 2 yaín s episch bzw. ionisch für $\gamma \tilde{\eta} \varsigma$.

\footnotetext{
${ }^{16}$ Recht verbreitet ist dieses Motiv hingegen insbesondere auf Giebelstelen aus dem Territorium von Amaseia (vgl. etwa Studia Pontica III 110a; 147; 155; 158; 164). Da dieses nur wenige Kilometer südwestl. von Eynekaraca beginnt (vgl. zum Grenzverlauf die Überlegungen zur Zugehörigkeit von Budakdere/Ladik zu Neoklaudiopolis oder Amaseia in Sauer - Olshausen 2018, 133 mit Lit.), weckt das den Verdacht, die Stelle könnte über die Polisgrenze hinweg verschleppt und eigentlich Amaseia zuzuordnen sein.
} 


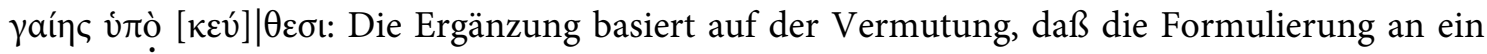
episches Vorbild angelehnt ist. ${ }^{17}$ Sollte sie zutreffen, liegt möglicherweise ein Epigramm vor; zumindest wäre der Anfang des Text daktylisch rhythmisiert.

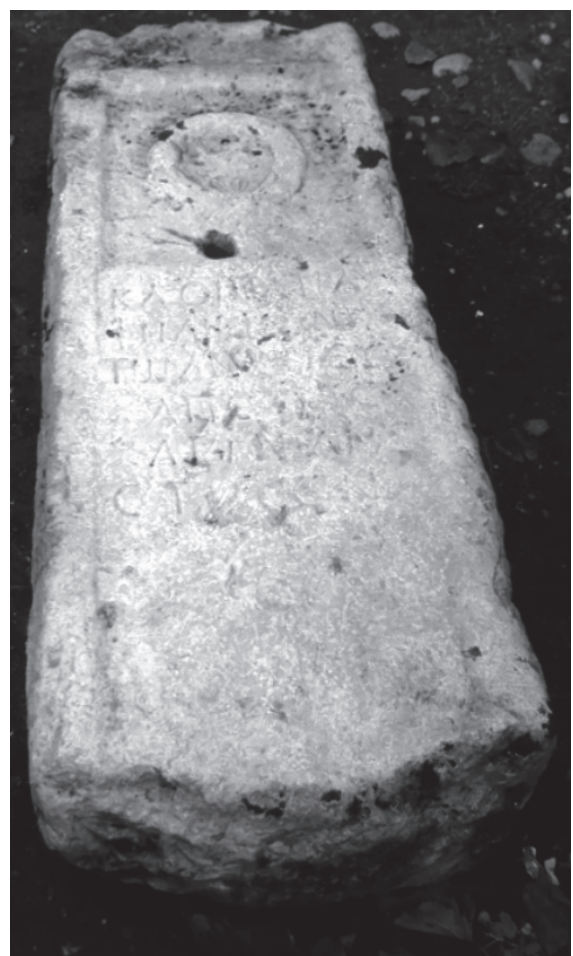

Abb. 9) Nr. 5 Für Phēlikiōn

\section{Nr. 5 Für Phēlikiōn}

Havza (26km südöstl. Vezirköprü). Im Hof des Nuri Salman. Soll aus Aşağı Susuz (4,7km südöstl. Havza) stammen; tatsächlich wußte man dort von einer Inschrift, die nach Havza gebracht worden war. 1990 (Photos, Abklatsch, Skizze der Stele, Abschrift).

Giebelstele. Kalkstein. Giebel- und Schriftfeld vertieft. Im Feld des recht flachen Giebels kein Dekor erkennbar. Im Schriftfeld ober- und unterhalb der Inschrift ein jeweils nochmals etwas eingetieftes Bildfeld. Im oberen Bildfeld Kranz mit Schleife, im unteren schemenhafte Reste mehrerer Gegenstände. Giebelspitze abgeschlagen, Akrotere bestoßen. Der untere Abschluß der Stele fehlt. Das obere Bildfeld ist unterhalb des Kranzes durchbohrt, darin Reste eines Metallrohres; offenkundig war die Stele in einem Brunnen verbaut. Mörtelanhaftungen.

H $130 \mathrm{~cm}$; B oben $46 \mathrm{~cm}$, unten $50 \mathrm{~cm}$; T 30cm. Bh. 3,2$4,0 \mathrm{~cm}$.

Alpha: Querstrich waagrecht. Epsilon: lunar. Pi: Deckstrich ragt über die Hasten hinaus. Sigma: lunar. Phi: Haste lang, Körper queroval. Omega: $\omega$-förmig, wobei die äußeren `Hasten rallel stehen. Alpha und Lambda teils mit Apices.

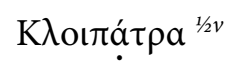

$$
\begin{aligned}
& \Phi \eta \lambda \iota \kappa^{\prime} \omega v \iota^{1 / 2 v}
\end{aligned}
$$

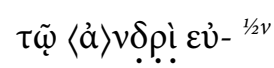

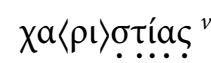

$$
\begin{aligned}
& \sigma \tau \underline{\sigma \varepsilon v^{1 / 2 v}}
\end{aligned}
$$

$5 \quad \chi \alpha ́ \rho ı v a ̀ ่ v \varepsilon ́-$

Kloipatra hat dem Phēlikiōn, ihrem Mann, aus (Dankbarkeit) (die Stele) aufgestellt.

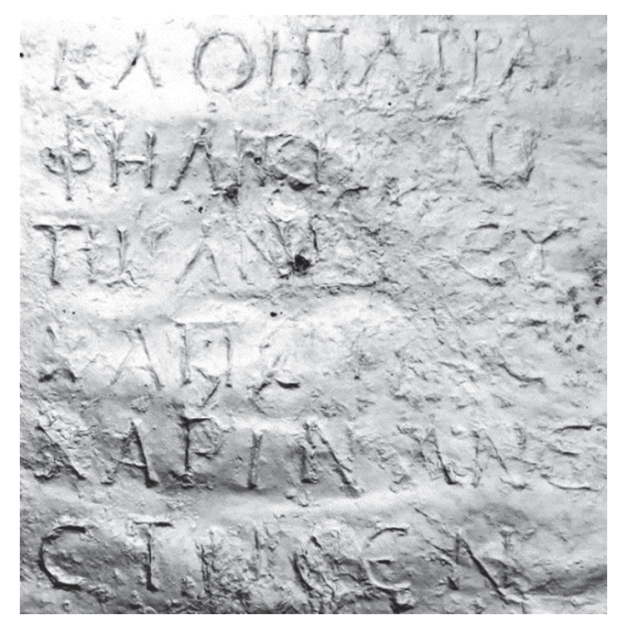

Abb. 10) Nr. 5 Für Phēlikiōn

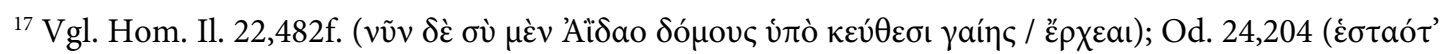

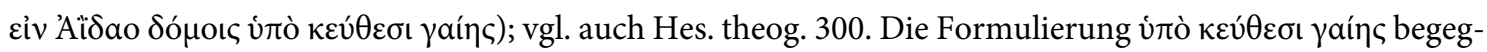
net auch in (anderen) Grabepigrammen: Peek 1942, 136-139 Nr. 306 = SEG 26, 290 (aus Kephisia/Attika); I.Égypte métriques 24 = SEG 24,1216 (aus Chenoboskion/al-Qașr). 
Die Oberfläche des Schriftfelds ist vor allem in der Mitte der Zeilen beschädigt, aber auch im Bereich der Buchstaben Chi am Anfang der Z. 4 und 5. (Chi ist dennoch in beiden Fällen sicher lesbar.)

Z. 1 K入oıтá $\tau \rho \alpha$ : Der Querstrich des Alpha ist nicht zu erkennen; unklar ist, ob dies an der Beschädigung liegt, oder ob der Steinmetz ihn nicht ausgeführt hat.

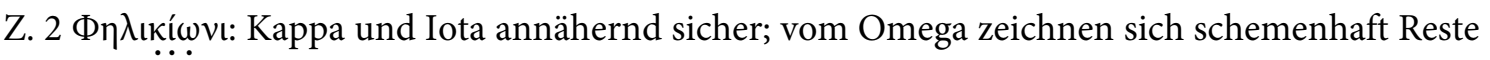
$\mathrm{ab}$.

Z. $3\langle\dot{\alpha}\rangle v \delta \rho ̣$ : Der Steinmetz hat das Alpha unvollständig gelassen: der Querstrich fehlt. Delta, Rho und Iota annähernd sicher.

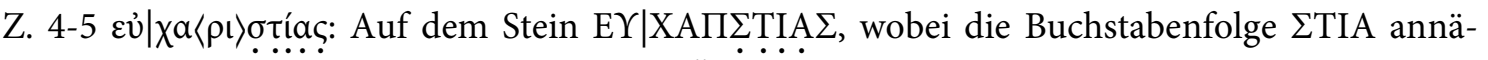
hernd sicher ist. Rho und Iota mögen beim Übertragen von einer vielleicht etwas undeutlichen Vorlage zu Pi verschmolzen sein.

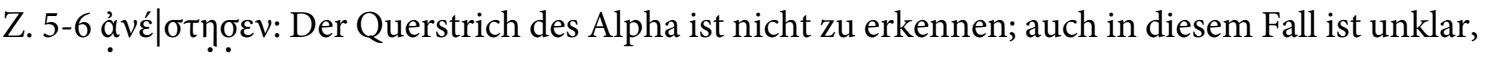
ob dies an der Beschädigung liegt, oder ob der Steinmetz ihn nicht ausgeführt hat. Eta und Sigma annähernd sicher.

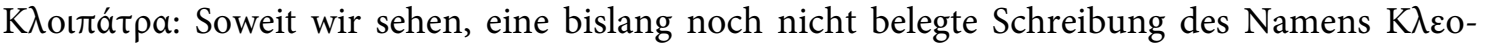
$\pi \alpha ́ \tau \rho \alpha$.

\section{Nr. 6 Für Antiochis}

Ilıca/Havza (10,4km nordnordöstl. Havza; 21,6km ostsüdöstl. Vezirköprü). Diente als Auflager einer Holztreppe an der Scheune des Aslanoğlu Ali Alıcı. 1989 (Photos, Abklatsch, Skizze der Stele, Abschrift). 2013 zusammen mit anderen Inschriften in einer kleinen Grünanlage des Ortes aufgestellt. ${ }^{18}$ Mittlerweile im Samsun Arkeoloji ve Etnografya Müzesi.

Giebelstele. Kalkstein. Giebel- und Schriftfeld vertieft. Im Giebelfeld Spiegel. Im Schriftfeld un-

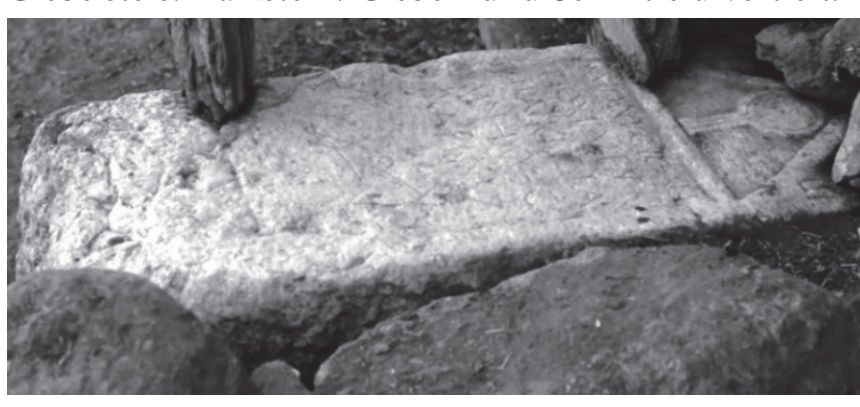

Abb. 11) Nr. 6 Für Antiochis (1989) terhalb der Inschrift mittig ein großes (Efeu-)Blatt an kurzer Ranke (graviert). Akrotere mit stilisierten, nach außen geschwungenen Blättern.

H $103 \mathrm{~cm}$; $46 \mathrm{~cm} ;$ T $31 \mathrm{~cm}$. Schriftfeld: H $52 \mathrm{~cm}$; B 32,5cm. Bh. 3,0-4,0cm.

Manche Buchstaben wirken recht ungelenk. Alpha: Querstrich waagerecht. My: wie zwei sich berührende Lambda, in einem Fall mit Apices, in einem Fall ohne. Ny: in Z. 1 ist beim ersten Ny die zweite Haste geschwungen, in Z. 5 stehen die Hasten schräg, sonst senkrecht. Sigma: lunar. Tau: asymmetrisch (der Deckstrich ragt links nur wenig über die Haste hinaus). Ypsilon: annähernd V-förmig. Alpha und Delta mit mal mehr, mal weniger ausgeprägten Apices.

${ }^{18}$ Gesehen im Rahmen eines Surveys des an der Süddänischen Universität angesiedelten Projekts »Where East meets West . 


$$
\begin{aligned}
& \Delta \text { เovv́бıุ 'Av- } \\
& \tau ı \chi^{\prime} \delta \mathrm{\iota} \gamma \mathrm{-}^{v} \\
& \text { vaıkì ióía } \\
& \mu \nu \eta ́ \mu \eta \varsigma \\
& 5 \chi \alpha \alpha^{\prime} \rho v^{1 / 2 v} ?^{1 / 2 v} \\
& \text { vac. hedera vac. } \\
& \text { vacat - 1-2 Zeilen - }
\end{aligned}
$$

Dionysis der Antiochis, seiner eigenen Frau, des Gedenkens wegen.

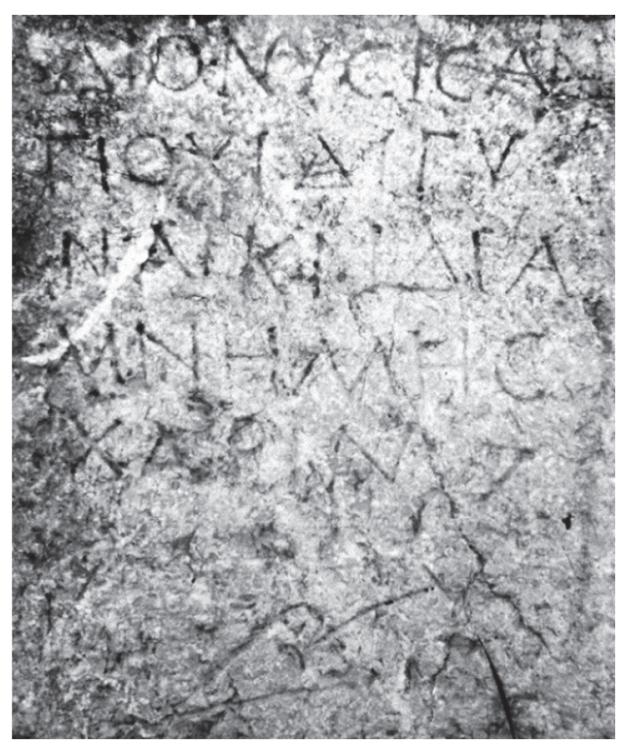

Abb. 12) Nr. 6 Für Antiochis (2013)

Z. 5 Am Ende der Zeile ein hakenförmiges Zeichen (ähnlich einer arabischen 7), wohl um, wie eine hedera, den Leerraum zu füllen.

\section{Nr. 7 Für Iustus Vespasianus}

Ilıca/Havza (10,4km nordnordöstl. Havza; 21,6km ostsüdöstl. Vezirköprü). Im Dorfbrunnen unterhalb des Wasserrohrs vermauert. 1989 (Photos, Abklatsch, Skizze des Steins, Abschrift).

Fragment sicherlich einer Stele. Kalkstein. Schriftfeld vertieft, vollständig erhalten. Von Sinter und Algen überzogen.

H $80 \mathrm{~cm}$; B $47 \mathrm{~cm}$. Schriftfeld: H 48cm; B $35 \mathrm{~cm}$. Bh. $5 \mathrm{~cm}$ in Z. 1-6, 4,5cm in Z. 7; in Z. 1 Omikron klein $(2,5 \mathrm{~cm})$ und hochgestellt, offenkundig aus Platzmangel. In Z. 7 sind die Buchstaben etwas in die Breite gezogen und haben größere Abstände zueinander, sicherlich um die Zeile trotz der geringen Buchstabenzahl zu füllen.

Alpha: Querstrich waagrecht. Epsilon: eckig. Eta: Querstrich unverbunden. My: kursiv. Ny: Diagonale setzt am oberen Ende der linken Haste an, endet aber oberhalb des unteren Endes der rechten Haste. Pi: Deckstrich ragt über die Hasten hinaus. Sigma: eckig. Ypsilon: V-förmig, Arme geschwungen. Omega: eckig mit parallel stehenden Hasten. Alpha und Delta mit Apices. Teils serifenartiger Ansatz.

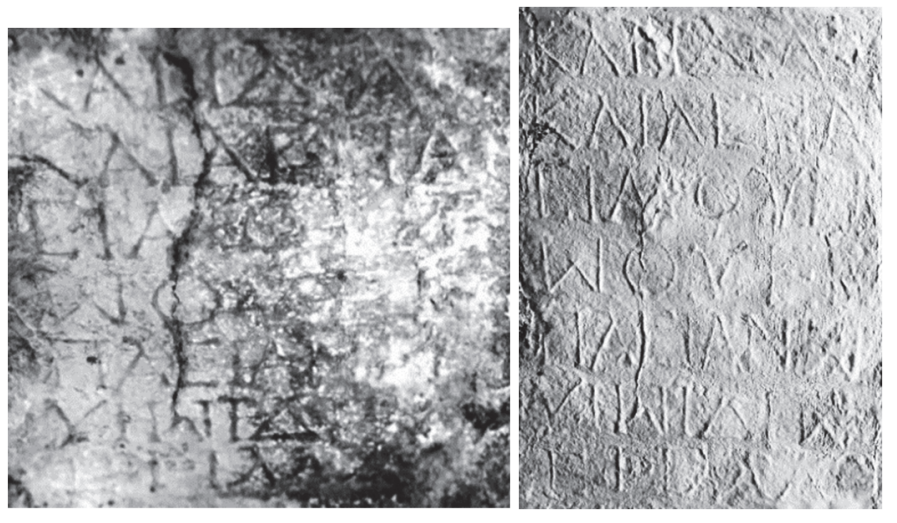

Abb. 13-14) Nr. 7 Für Iustus Vespasianus (Abb. 13: Photo verzerrt)

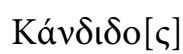

кaì Aora-

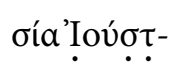

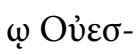

$5 \pi \alpha \sigma \iota \alpha v \tilde{\omega}$

vị̂̃ ióí

$\sigma \tilde{\eta} \mu \alpha^{1 / 2 v}$
Candidus und Aspasia (haben) Iustus Vespasianus, ihrem eigenen Sohn, den Grabstein (aufgestellt). 


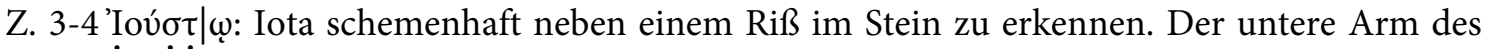
Sigma ist so kurz, daß man den Buchstaben fast für ein Gamma halten könnte. Vom Tau ist nur die Haste gut erkennbar. Aus Platzmangel wurde höchst wahrscheinlich ein wohl etwas verkleinertes Tau gleichsam unter das Sigma geschrieben - und zu diesem Zweck dessen unterer Arm gekürzt.

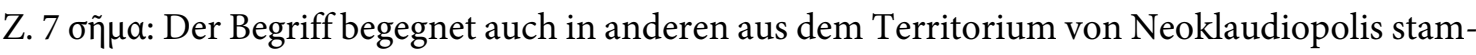
menden Inschriften. Anders als bei der hier vorliegenden handelt es sich dabei aber, soweit beurteilbar, um metrische bzw. stilistisch ambitionierte Inschriften. ${ }^{19}$

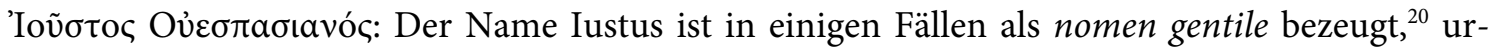
sprünglich und in aller Regel ist er aber cognomen, und der Name Vespasianus begegnet außerhalb des flavischen Kaiserhauses nur höchst selten. ${ }^{21}$ So wirkt der Name Iustus Vespasianus insgesamt in gewisser Weise unecht: Es drängt sich der Verdacht auf, daß der Verstorbene nicht etwa römischer Bürger gewesen ist, sondern sein Name lediglich dem Bemühen der Familie geschuldet war, sich möglichst römisch zu geben und daher im Fall des Sohnes die Namensgebung römischer Bürger gleichsam zu simulieren. Unabhängig davon, ob dieser Verdacht das Richtige trifft, fragt es sich, was die Familie zur Wahl des Namens Vespasianus veranlaßt hat und, verbunden damit, ob sich daraus gar ein Indiz für die Datierung der Inschrift ergibt.

\section{Nr. 8 Für Hostilia Kyriakē}

Karkucak/Vezirköprü (4,5km südsüdwestl. Vezirköprü). Im Hof eines Bauern. 1990 (Photos, Abklatsch, Skizze der Stele, Abschrift).

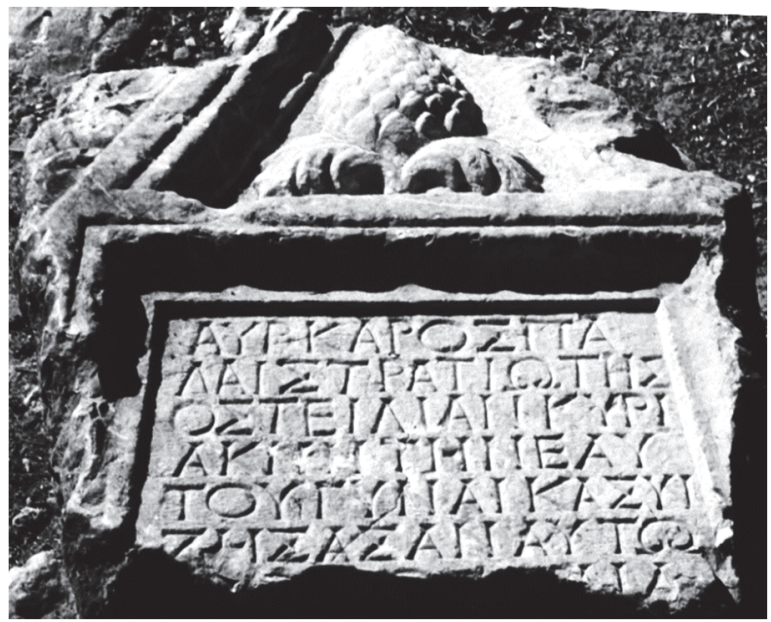

Abb. 15) Nr. 8 Für Hostilia Kyriakē

Fragment einer sich nach oben leicht verjüngenden Giebelstele. Kalkstein. Giebel- und Schriftfeld vertieft, jeweils von profiliertem Rahmen umgeben. Im Giebelfeld ein Pinienzapfen auf zwei Akanthusblättern; Relief auffallend plastisch. Hinsichtlich der Steinmetzarbeit sicherlich eine der qualitätvollsten Grabstelen aus dem Territorium von Neoklaudiopolis. Giebelspitze und Akrotere erheblich bestoßen, ebenso der Rahmen links und rechts des Schriftfelds und rechts des Giebelfelds. Unten gebrochen.

${ }^{19}$ Metrisch: Studia Pontica III 58 = Steinepigramme II 11/05/02; Studia Pontica III 77a = Steinepigramme II 11/03/03; unten Nr. 9. Stilistisch ambitioniert: Marek - Adak 2016, 80 Nr. 88 = SEG 66, 1548

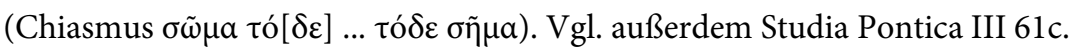

${ }^{20}$ Vgl. Schulze 1904, 294; Solin - Salomies 1994 s.v.; außerdem I.Gerasa 157 und 158 (mit Haensch 1993, 171f.).

${ }^{21}$ CIL 3, 12014, 577 = 14133, 2 (vgl. Kajanto 1965, 158); außerdem CIL 8, 9956 (471 n.Chr.), Camodeca 2002, 228 (43 n.Chr.) und wohl auch De Rossi 1979, 62. 
H 53cm; B 39cm; T $20 \mathrm{~cm}$. Schriftfeld: H $22 \mathrm{~cm}$ erhalten; B oben $26 \mathrm{~cm}$, auf Höhe der Bruchkante $28 \mathrm{~cm}$. Bh. $2,5 \mathrm{~cm}$.

Alpha: Querstrich waagrecht. Epsilon: eckig. Eta: in Z. 2 Querstrich verbunden, in Z. 4 (6. Buchstabe) und 6 unverbunden. Sigma: $\Sigma$-förmig. Ypsilon: Arme meist leicht geschwungen. Omega: $\Omega$-förmig, wobei das `Hufeisen in kleine Innenbogen ausläuft. Serifen.

Ligatur: Z. 5 YN am Zeilenende.

\begin{tabular}{|c|c|}
\hline \multicolumn{2}{|c|}{ 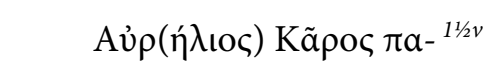 } \\
\hline & $\lambda \alpha \iota \sigma \tau \rho \alpha \tau \iota \omega ́ \tau \eta\rceil$ \\
\hline & 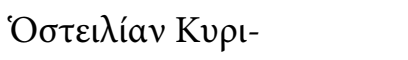 \\
\hline & 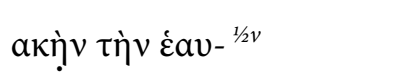 \\
\hline 5 & 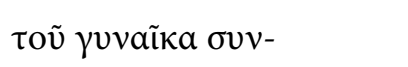 \\
\hline & $\zeta \eta ́ \sigma \alpha \sigma \alpha v a \dot{v} \tau \tilde{\omega}$ \\
\hline & {$[\ldots .] ?.[.$.$] ?. { }^{v}$} \\
\hline
\end{tabular}

Aurelius Carus, Veteran, die Hostilia Kyriakē, seine Frau, die mit ihm zusammengelebt hat (sc. ehrend) ...

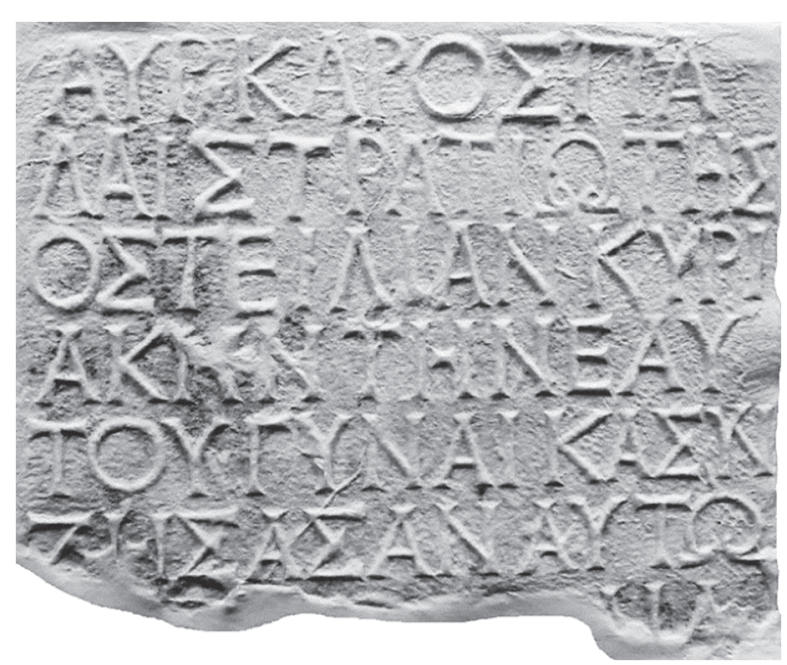

Abb. 16) Nr. 8 Für Hostilia Kyriakē

Z. 3-4 Kvpı|akṇ́v: Querstrich des Eta nicht erkennbar.

Z. 7 [....]?[..]?IA ${ }^{v}$ : Auf wohl vier Buchstaben folgt ein oben gerundeter Buchstabe, danach folgt auf

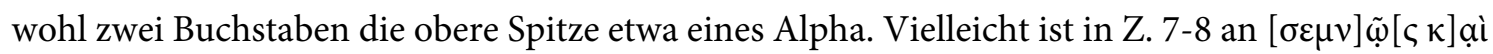
$\dot{\alpha}^{v} \mid[\mu \varepsilon ́ \mu \pi \tau \omega \varsigma---]$ zu denken.

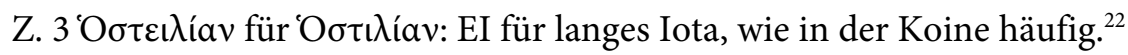

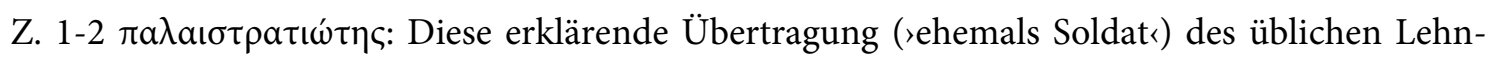

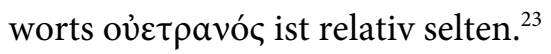

Offenkundig hat man auf syllabische Worttrennung Wert gelegt: vgl. die vacat-Stellen am Ende der Z. 1, 4 und und wohl auch 7 und die Ligatur am Ende von Z. 5.

Sowohl Aurelius Carus als auch seine verstorbene Frau, Hostilia Kyriakē, waren römische Bürger. Seit wann sie das Bürgerrecht besaßen, ist nicht zu sagen: Carus könnte es erst aufgrund seines Militärdienstes erhalten, oder aber schon zuvor besessen haben; ${ }^{24}$ Kyriakē könnte eine Freigelassene gewesen sein oder aber aus einer Familie stammen, die das Bürgerrecht schon länger besaß, wobei ein direkter italischer Hintergrund wenig wahrscheinlich, aber auch nicht gänzlich ausge-

\footnotetext{
${ }^{22}$ Vgl. Brixhe 2010, 232.

${ }^{23} \mathrm{Vgl}$. aber etwa I.Ankara 1, 190; zum terminus vgl. den Kommentar ebenda und besonders Robert 1938, $157 f$.

${ }^{24} \mathrm{Zu}$ den Implikationen des nomen gentile Aurelius selbst vgl. in aller Kürze Sauer - Olshausen 2021, zu Nr. 2.
} 
schlossen ist. Andere Träger des nomen gentile Hostilius sind in Neoklaudiopolis bislang nicht nachgewiesen. ${ }^{25}$

Der Name Kyriakē läßt, wenn auch nicht mit Sicherheit, so doch mit großer Wahrscheinlichkeit darauf schließen, daß die Verstorbene Christin gewesen ist. ${ }^{26}$ Bislang ist aus dem Territorium von Neoklaudiopolis allenfalls eine weitere Trägerin dieses Namens bekannt. ${ }^{27}$ Kyriakos, das männliche Pendant dieses Namens, ist in Neoklaudiopolis für drei Personen bezeugt; einer der Männer war fraglos Christ, der zweite mit annähernder Sicherheit, der dritte wiederum mit immerhin recht großer Wahrscheinlichkeit. ${ }^{28}$

Mit Aurelius Carus sind in Neoklaudiopolis nun insgesamt zehn Militärangehörige inschriftlich faßbar: Zwei beneficiarii - der eine erhielt eine Ehreninschrift, ${ }^{29}$ der andere starb hier während seiner Dienstzeit ${ }^{30}$-, ein हैं $\pi \alpha \rho \chi o \varsigma$ - er war wohl praefectus classis Ponticae ${ }^{-31}$ und sieben Soldaten, die sich hier als Veteranen ansiedelten, wobei zumindest einer von ihnen auch in Neoklaudiopolis geboren war, ein anderer jedoch aus Nikomedeia stammte. ${ }^{32}$ Die Veteranen - selbstredend auch

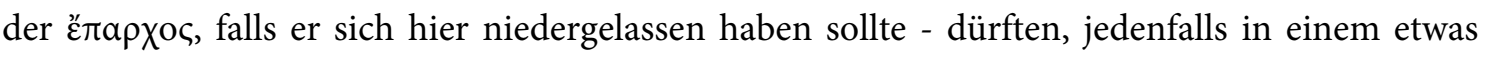

\footnotetext{
${ }^{25}$ Soweit wir sehen, gilt dies auch für die Nachbarstädte; nach freundlicher Auskunft von Christian Marek insbesondere auch für Pompeiopolis. Überhaupt ist es in Kleinasien recht selten, wobei jedoch für Nikaia eine gewisse Häufung festzustellen ist: I.Mus. Iznik 34; 1161; Adak - Akyürek Şahin 2005, 145f. Nr. 12 = SEG 55,

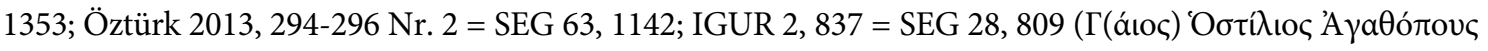

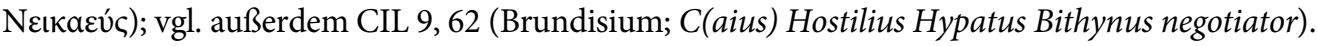

${ }^{26}$ Vgl. etwa den Kommentar von Ulrich Huttner zu ICG 1295, d.i. MAMA 7, 297 = Waelkens 1986, 210 Nr. 518: „Calder und Waelkens gehen davon aus, daß der Name Kyriake in Kleinasien immer christlich sei. Diese These bleibt zu überprüfen. Unbestritten ist die Beliebtheit des Namens Kyriake bei den Christen." Vgl. außerdem Kajanto 1963, 104, insbesondere auch zum unterschiedlichen Verständnis des Namens in paganem und christlichem Kontext (»semantic shift«).

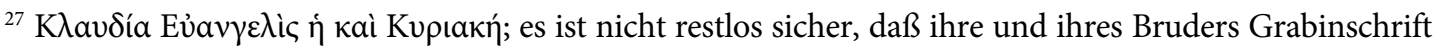
(Sauer - Olshausen 2018, 133-136 Nr. 6) Neoklaudiopolis zuzurechen ist. - Daß Kyriakē nicht etwa `nur $\bullet \operatorname{cog}$ nomen, sondern agnomen der Claudia gewesen ist, kann kaum als zusätzliches Indiz dafür gewertet werden, daß sie Christin gewesen ist, die Zubenennung gar mit der Annahme des Christentums in Verbindung stand: Claudia verstarb offenbar in jungen Jahren und wurde von ihren Eltern gemeinsam mit ihrem Bruder Gaius Claudius Kallistus bestattet, der kein entsprechendes agnomen trägt. Zum Phänomen der Zubenennung vgl. etwa Horsley 1992, speziell zu Zubenennungen in christlichem Kontext auch Kajanto 1963, 118-121.

${ }^{28}$ Vgl. Studia Pontica III 55 (Diakon) bzw. Studia Pontica III 91 = Steinepigramme II 11/05/01 (attestiert seinen Eltern insbesondere auch, > Gott in reiner Weise verehrt ‘ zu haben; vgl. Marek 2003, 122) bzw. Studia Pontica III 63 (hier ist der Name einziges Indiz).

${ }^{29}$ Marek - Adak 2016, 77f. Nr. 84. Wir möchten zu überlegen geben, ob in dieser lateinischen Inschrift gratulandi causa weniger im Sinn einer Gratulation als vielmehr im Sinn von >um Dankbarkeit zu zeigen zu verstehen ist.

${ }^{30}$ Bekker-Nielsen - Høgel - Sørensen 2015, 119-122 Nr. 3 = SEG 65, 1208.

${ }^{31}$ Studia Pontica III 92 = SEG 29, 1366 = 33, 1095 = 57, 1296; vgl. auch Wheeler 2012, 131 Anm. 45, 145f. mit Anm. 110.

${ }^{32}$ Studia Pontica III 34 (aus Neoklaudiopolis); 41 = SEG 13, 527; 49; 69 (aus Nikomedeia); 70; 90.
} 
weiteren Sinn, zur Elite der Gesellschaft von Neoklaudiopolis gehört haben; zumindest einer von ihnen war Mitglied der boule..$^{33}$

\section{Nr. 9 Gestiftet von Bromios}

Ortaklar/Havza (11km nordwestl. Havza; 15,4km südsüdöstl. Vezirköprü). Im Hof des Asım Gönen. 1989 (Photos, Abklatsch, Skizze der Stele, Abschrift).

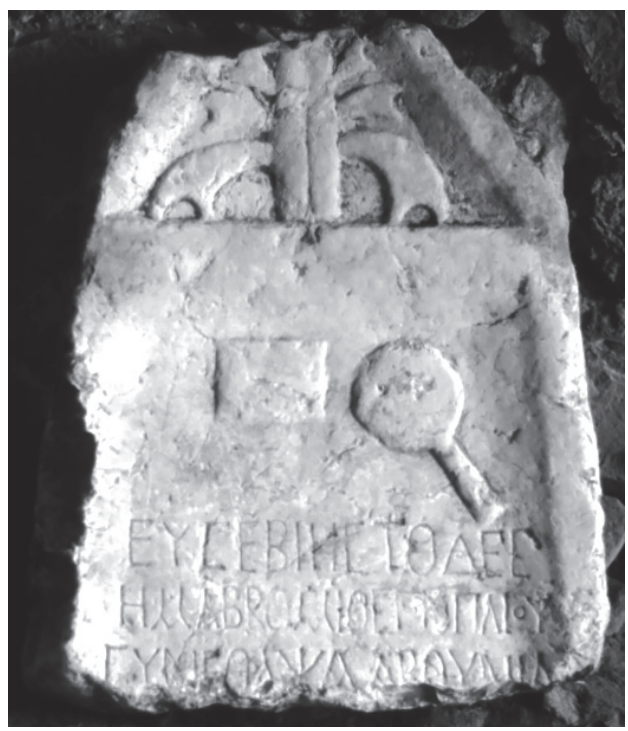

Abb. 17) Nr. 9 Gestiftet von Bromios

Fragment einer sich nach oben leicht verjüngenden Giebelstele. Kalkstein. Giebel- und Schriftfeld vertieft, links und rechts zum Rahmen hin angeschrägt. Auffallend ist der sanfte Übergang vom Schriftfeld zu dem zwischen Giebel- und Schriftfeld liegenden Steg im Gegensatz zu der gleichsam harten Kante dieses Stegs zum Giebelfeld hin. Im Giebelfeld Pflanze mit dickem, längsgekerbtem Stengel und unten großen, oben kleineren gegenständig angeordneten Blättern. ${ }^{34} \mathrm{Im}$ Schriftfeld oberhalb der Inschrift ein rechteckiger Gegenstand - höchst wahrscheinlich ein Kamm - und ein Spiegel. Giebelspitze abgeschlagen; Akrotere und linker Rahmen des Schriftfelds bestoßen; unten gebrochen.

$\mathrm{H} 61 \mathrm{~cm} ;$ B $51 \mathrm{~cm} ; \mathrm{T} 15 \mathrm{~cm}$. Schriftfeld: $\mathrm{H} 37 \mathrm{~cm}$ erhalten; B 43cm. Bh. in Z. 1 meist 3,9-4,4 cm, Delta 3,2cm; in Z. 2 meist 3,3-3,7cm, vorletzter Buchstabe (Omikron) 1cm. Alpha: Querstrich gebrochen. Epsilon: eckig. Theta: länglich. My: kursiv. Omikron: länglich, außer Z. 2 vorletzter Buchstabe (rund, klein). Sigma: eckig. Alpha teils mit Apex.

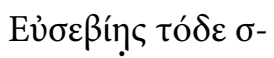

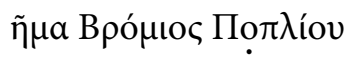

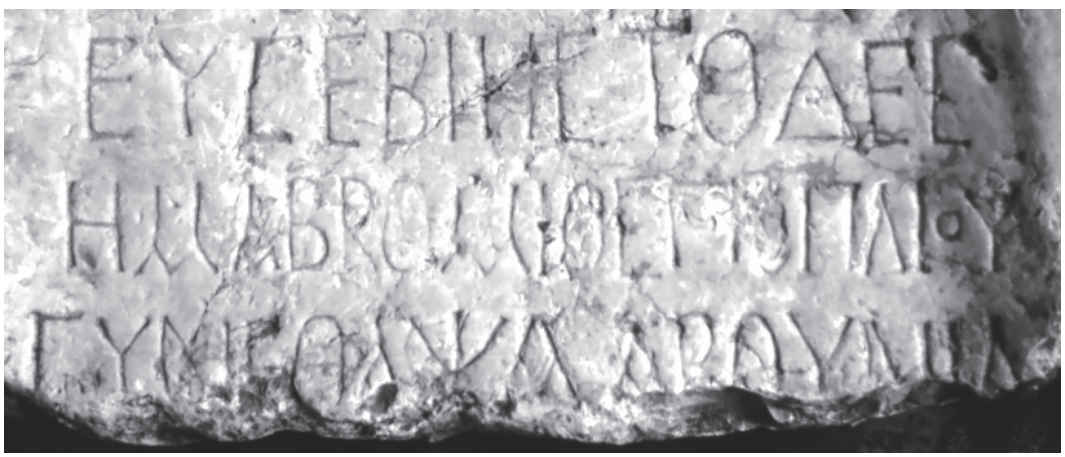

Abb. 18) Nr. 9 Gestiftet von Bromios

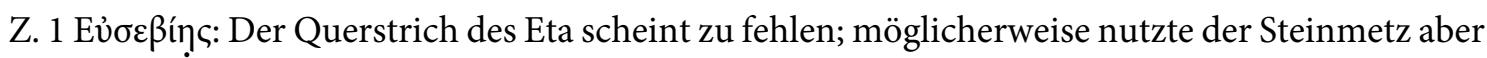
einen Fehler des Steins und führte den Querstrich diagonal aufsteigend entlang dieses Risses.

\footnotetext{
${ }^{33}$ Studia Pontica III 41.

${ }^{34}$ Mit einiger Sicherheit ist eine derartige Pflanze auch auf einer anderen ebenfalls aus Ortaklar stammenden Stele dargestellt, ebenfalls im Giebelfeld (Sauer - Olshausen 2021, Nr. 4). In diesem zweiten Fall sind zwar die Blätter kaum erkennbar, sehr gut aber das, was man für einen dicken Stengel (wenngleich ohne Kerbe) und eine kugelförmige Blüte halten kann. Vgl. auch die Pflanzendarstellung im Giebelfeld der Stele Olshausen 1987, 84f. Nr. 3, Taf. 8 Abb. 3a, die möglicherweise ebenfalls aus Neoklaudiopolis stammt (vgl. Sauer - Olshausen 2018, 125 mit Anm. 5).
} 
Z. 2 По $\pi \lambda$ íov: Die obere Hälfte des Omikron ist beschädigt. Möglicherweise Compendium OY (Omikron mit oben aufgesetzten Armen des Ypsilon).

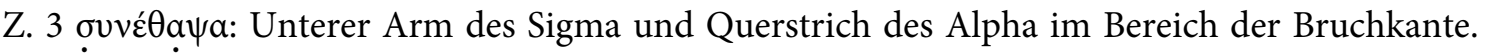
Aß̣ouviạ: Rho statt Beta ist nicht gänzlich ausgeschlossen. Der linke Ansatz des Querstriches des Alpha ist recht sicher erkennbar.

Am Ende fehlen vermutlich mehrere Zeilen.

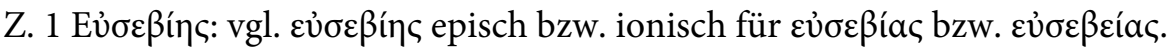

Worttrennung in Z. 1 nicht syllabisch.

Aßouvıa: Der Name könnte etwa Aßovvía oder 'Aßouvíac lauten. Soweit wir sehen, ist er in griechischen Quellen bislang nicht nachgewiesen. Entsprechendes gilt, liest man Rho für Beta bzw. Lambda oder Delta für Alpha. Möglicherweise ist freilich die feminine Form eines der römischen nomina gentilia Abonius, Habonius, Avonius oder auch Aronius gemeint. ${ }^{35}$

Der Text beginnt metrisch. Wie er im Detail zu verstehen ist, ist nicht mit letzter Sicherheit zu

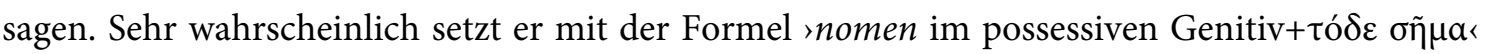
ein. ${ }^{36} \mathrm{Zu}$ verstehen ist dann >dies ist das Grab/der Grabstein der Eusebia oder >dieses Grab/diesen Grabstein der Eusebia (habe ich), Bromios, Sohn des Publius (angelegt/errichtet)<, nicht etwa >die-

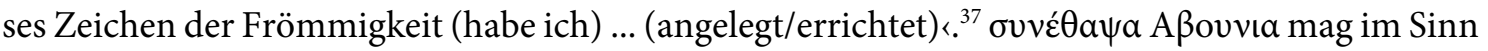
von >ich, Bromios, habe gemeinsam mit >Abounia (jemanden, ggf. Eusebia) bestattet zu verstehen sein. ${ }^{38}$ Nicht ausgeschlossen ist aber auch, daß gemeint ist, >ich, Bromios, habe >Abounia mitoder auch hinzubestattet (ggf. mit oder zu Eusebia hinzu) $\times .^{39}$

\section{Nr. 10 Für Antonia}

Yağcı/Vezirköprü (6,6km südöstl. Vezirköprü). Im Gras liegend. 1989 (Photos, Abklatsch, Skizze der Stele, Abschrift). 2014 in einer niedrigen Mauer verbaut wiedergesehen. ${ }^{40}$

${ }^{35} \mathrm{Zu}$ diesen nomina vgl. Schulze 1904, 66, 72, 125; Solin - Salomies 1994, s.v. Habonius. Zur Schreibung OY für lateinische o-Laute vgl. Brixhe 1987, 56.

${ }^{36}$ Vgl. zu dieser Formel, insbesondere zu ihrem Zusammenhang mit Hom. Il. 7,89f. und zu ihrer Häufigkeit als Eröffnung von Grabepigrammen, Staab 2018, 71, 168. In Neoklaudiopolis begegnet sie in Studia Pontica III 58 = Steinepigramme II 11/05/02.

${ }^{37}$ Vgl. aber die Inschriften Studia Pontica III 68b = Marek - Adak 2016, 77 Nr. 83 = SEG 66, 1542 und

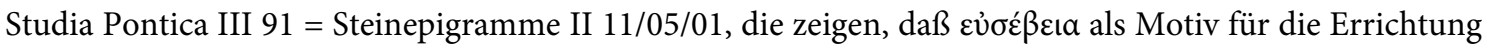
einer Grabstele auch in Neoklaudiopolis hin und wieder expressis verbis angeführt wurde.

${ }^{38}$ In diesem Fall wäre A $\beta$ ouvıa als Dativus sociativus der mithandelnden Person aufzufassen (also etwa 'Aßovvíạ). Zum Komitativ bzw. Dativus sociativus bei Komposita mit ouv-vgl. Schwyzer 1950, 160.

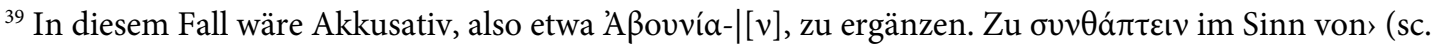
nachträglich) hinzubestatten`vgl. IG XIV 943 = IG Porto 53 mit dem Kommentar Harter-Uibopuu 2013, 180.

${ }^{40}$ Wir danken Bünyamin Kıvrak/Vezirköprü für die freundliche Mitteilung. 


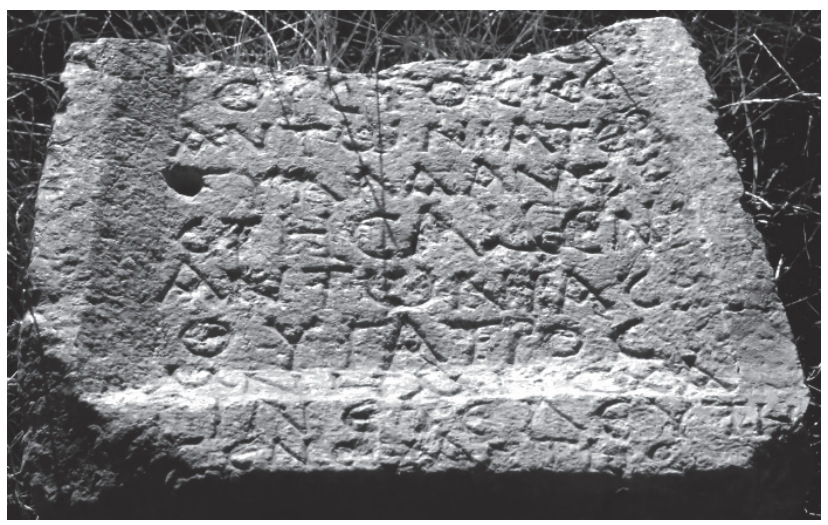

Abb. 19) Nr. 10 Für Antonia

Fragment einer sich nach oben leicht verjüngenden Stele. Kalkstein. Schriftfeld vertieft, zum Rahmen hin angeschrägt. Erster Buchstabe in Z. 4 durch eine Bohrung beschädigt. Oben gebrochen.

H $42,5 \mathrm{~cm}$; B oben $43 \mathrm{~cm}$, unten $47 \mathrm{~cm}$. Schriftfeld: H $29,5 \mathrm{~cm}$ erhalten; B unten $29 \mathrm{~cm}$. Bh. 2,5-4,5cm, meist 3,0-4,0cm.

In Z. 3 und 5 befindet sich der letzte Buchstabe ganz bzw. teilweise auf der Anschrägung zum Rahmen. Z. 8 liegt auf der Anschrägung zum unteren Rahmen, Z. 9 und 10 auf dem unteren Rahmen selbst. Die Z. 8 und 9 ragen rechts über die Breite des Schriftfelds hinaus. Alpha: Querstrich gebrochen. Epsilon: lunar. My: kursiv. Xi: Balken durch Diagonale verbunden. Sigma: lunar. Omega: $\omega$-förmig. Erstes Alpha in Z. 3 mit Apex. Teils leichter Ansatz zu Serifen.

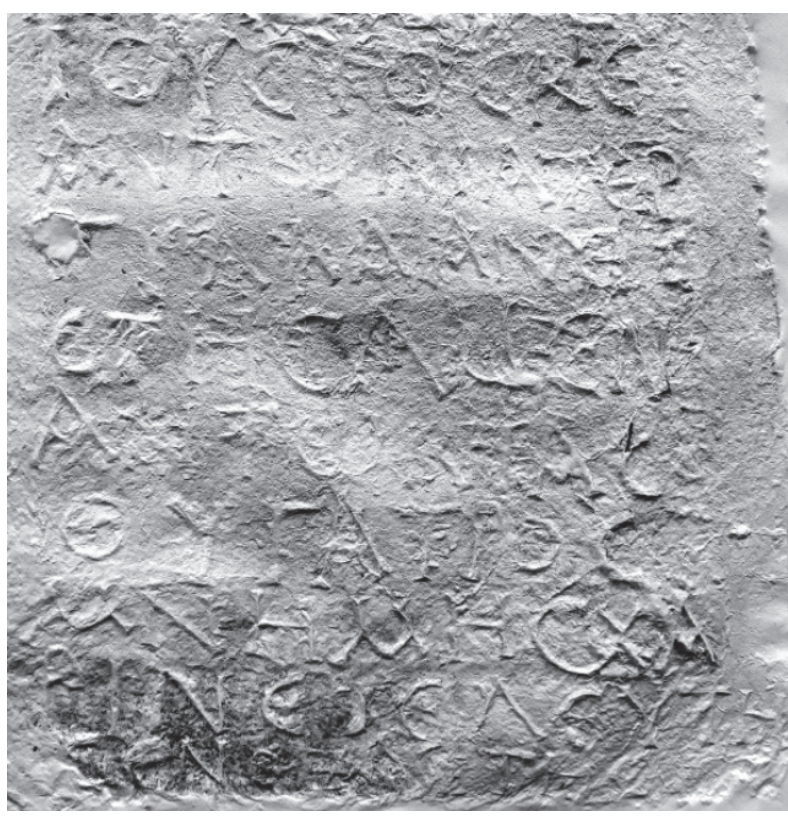

Abb. 20) Nr. 10 Für Antonia $\left[’ v^{\prime} \omega \dot{\omega} v i o\right] \varsigma$

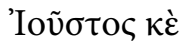

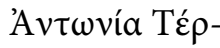

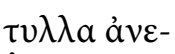

$5 \sigma \tau \eta ́ \sigma \alpha \mu \varepsilon v$

Avtwvíac

$\theta v \gamma \alpha \tau \rho \grave{\varsigma} \varsigma$

$\mu v \eta ́ \mu \eta \varsigma ~ \chi \alpha ́-$

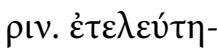

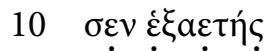

Wir, [Antonius] Iustus und Antonia Tertulla, haben (die Stele unserer) Tochter Antonia aufgestellt, des Gedenkens wegen. Sie starb sechsjährig.

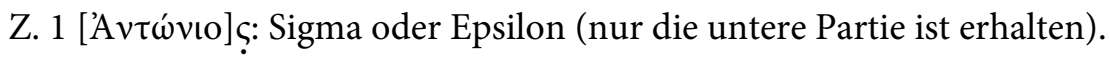

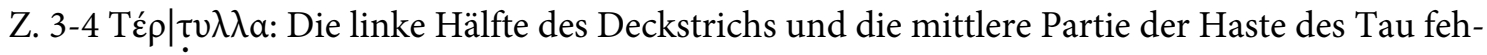
len.

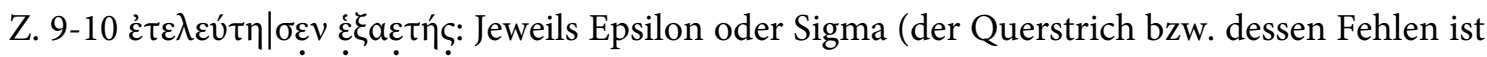
nicht sicher feststellbar).

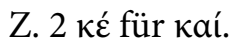

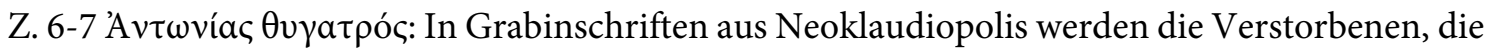

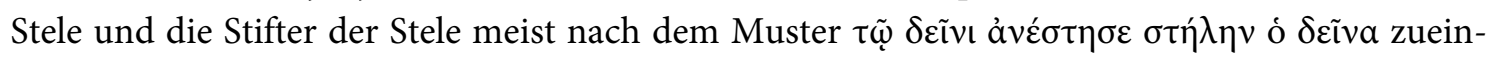




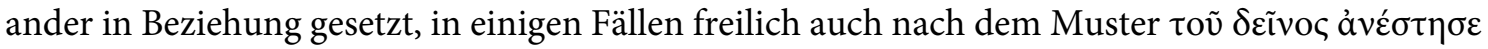
$\sigma \tau \hat{\eta} \lambda \eta v$ ó $\delta \varepsilon \tilde{v} v \alpha^{41}$ - so auch hier.

Antonia Tertulla und ihre Tochter besaßen sicherlich das römische Bürgerrecht. Will man nicht annehmen, daß die Tochter ihr Bürgerrecht und ihren Namen ihrer Mutter verdankte, ist anzunehmen, daß auch ihr Vater das nomen gentile Antonius trug. Denkbar wäre in diesem Fall insbesondere, daß Tertulla Freigelassene des Iustus gewesen ist oder daß Iustus und Tertulla miteinander verwandt waren. Angesichts der relativen Häufigkeit des nomen gentile Antonius in Neoklaudiopolis ${ }^{42}$ kann die Namensgleichheit aber auch schlicht Zufall gewesen sein.

\section{Nr. 11 Für eine im Alter von 18 Jahren Verstorbene}

Avdan/Vezirköprü (6,6km nordnordwestl. Vezirköprü). Im Stall des Hüseyin Çil vermauert. 1990 (Photos, Abklatsch, Skizze des Steins, Abschrift). 2014 wiedergesehen von Bünyamin Kıvrak, Vezirköprü. ${ }^{43}$

Fragment wohl einer Stele. Kalkstein. Schriftfeld vertieft, Rahmen profiliert. Erhalten ist die linke obere Ecke des Schriftfelds mit dem linken und dem Ansatz des oberen Rahmens.

H 50cm; B 34 cm. Bh. 5,5-6,0cm (Z. 1-5) bzw. 3,5cm (Z. 6).

Z. 1 eingerückt und mit etwas größerem Abstand zu den folgenden Zeilen; Z. 6 mit kleineren Buchstaben und geringerem Abstand zur voranstehenden Zeile. Alpha: Querstrich waagrecht (dabei auffallend hoch angesetzt), in Z. 1 aber aufsteigend. Epsilon: in Z. 3 eckig, in Z. 6 lunar. Theta: Querstrich unverbunden. Sigma: lunar. Xi: oberer und mittlerer Balken durch Diagonale verbunden, mittlerer Balken kurz und tief angesetzt. Ypsilon: Arme geschwungen. Dank deutli-

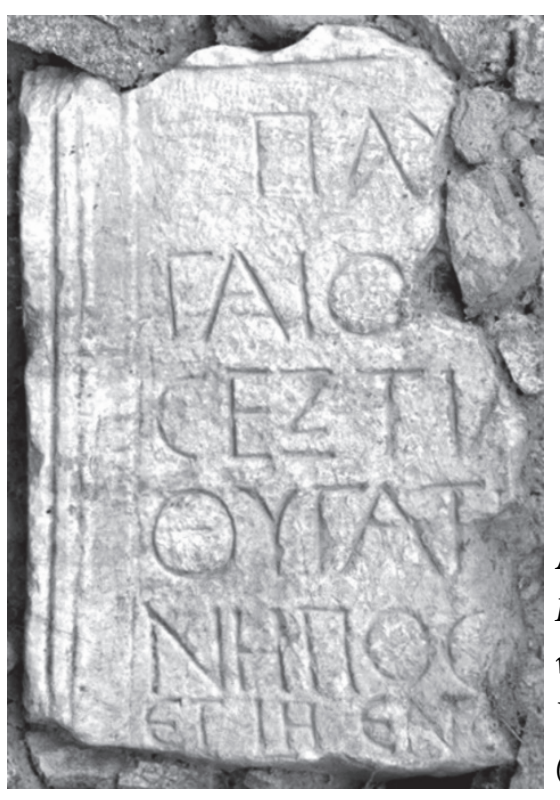
cher Unterschneidungen (Z. 1 AY, Z. 2 ГA, Z. 4 ГAT) wirkt die Schrift trotz der erheblichen Größe der Buchstaben harmonisch.

In Z. 6 machen Leerstellen die Zeichenfolgen ET bzw. IH als Abkürzung bzw. als Ziffer kenntlich.

Abb. 21) Nr. 11

Für eine im Alter

von 18 Jahren

Verstorbene

(Photo: Bünyamin

$$
\begin{aligned}
& { }^{1 / 2 v} \text { Пav[---] } \\
& \text { Гaıı[---] } \\
& \sum \varepsilon \xi \tau \iota a[---] \\
& \theta v \gamma a ́ \tau \eta ̣[\rho---] \\
& 5 \quad \mathrm{NHПО} \Sigma[---] \\
& \dot{\varepsilon} \tau(\tilde{\omega} v){ }^{v}{ }^{\prime} \eta^{\prime}{ }^{v} \text { EN? [---] }
\end{aligned}
$$

${ }^{41}$ Vgl. dazu Sauer - Olshausen 2021, Nr. 4.

${ }^{42}$ Vgl. Studia Pontica III 33; 49; 49a; 65; 77; 90; 92; Kahl 1995; Sauer - Olshausen 2018, 127f. Nr. 2; außerdem eine weitere noch unveröffentlichte Inschrift aus Yağcı und die Inschrift Olshausen 1987, 84f. Nr. 3, falls sie tatsächlich aus Neoklaudiopolis stammen sollte (vgl. Sauer - Olshausen 2018, 125 mit Anm. $5 \mathrm{zu}$ ihrem Fundort).

${ }^{43}$ Möglicherweise auch von Akın Temür und Davut Yiğitpaşa (vgl. Temür - Yiğitpaşa 2020, 2878). 
Z. $3 \sum \varepsilon \xi \tau ı \alpha$ [---: Alpha annähernd sicher: Der Querstrich zeichnet sich im Abklatsch recht deutlich ab.

Z. 4 Өvүát sie oben frei. So ist höchst wahrscheinlich Eta, nicht Rho und also Nominativ $\theta v \gamma a ́$ tๆ $\rho$ zu lesen.

Z. 5 NHПО nen, daß es sich um einen rechts offenen Bogen und also um Sigma handelt.

Z. 6 Vor der Bruchkante ist der linke Bogen eines gerundeten Buchstabens erhalten.

Die Inschrift gilt einer im Alter von 18 Jahren verstorbenen Person; ${ }^{44}$ die in Z. 4 Tochter genannte Person ist also sicherlich nicht die Stifterin der Inschrift, sondern die Verstorbene. Die in den Z. 1-3 erhaltenen Wortteile gehören zweifellos zu Namen, ${ }^{45}$ die optische Hervorhebung der ersten Zeile spricht - wenngleich nicht zwingend - dafür, daß der hier genannte jener der Verstorbenen

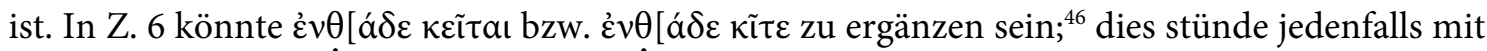
einer Nennung der Verstorbenen im Nominativ in Einklang. Das Ende der 4. und die 5. Zeile könnten eine Charakterisierung der Verstorbenen enthalten haben. Möglicherweise ist insgesamt also zu verstehen: Pau[lina], die ... Tochter des Gaius [nomen gentile] Sextia[nus], im Alter von 18 Jahren (verstorben), liegt hier.

\section{Nr. 12 Gestiftet von Basa}

Pazarc1/Vezirköprü (8,7km südsüdöstl. Veziröprü). In der Scheune des Nurettin Öztürk vermauert. 1989 (Photos, Abklatsch, Skizze der Fragmente, Abschrift).

Zwei Fragmente höchst wahrscheinlich derselben Stele. Fragment (a) - jenes mit der Inschrift wäre dann der mittlere, Fragment (b) der untere Teil. Kalkstein.

Fragment (a): Links der Scheunentür vermauert. Vertieftes Schriftfeld, oben und unten gebrochen. H $35 \mathrm{~cm}$; B $57 \mathrm{~cm}$; T $19 \mathrm{~cm}$. Schriftfeld: B $47 \mathrm{~cm}$. Bh. 4,0-5,0cm.

Fragment (b): Rechts der Scheunentür vermauert. Vertieftes (Schrift)feld, an einer - wohl der oberen - Seite gebrochen, unbeschriftet. H $33 \mathrm{~cm}$; B $57 \mathrm{~cm}$; T $20 \mathrm{~cm}$. (Schrift)feld: H $25 \mathrm{~cm}$ erhalten; B $47 \mathrm{~cm}$.

Alpha: Querstrich waagrecht. Epsilon: lunar. My: wie zwei sich berührende Lambda. Omikron: länglich. Rho: Bogen klein und länglich. Sigma: lunar, dabei recht schmal. Ypsilon: in einem Fall

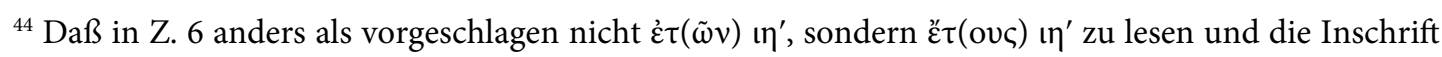
also in das Jahr 18 der städtischen Ära, d.h. in das Jahr 12/3 n.Chr. zu datieren wäre, ist angesichts des außergewöhnlich hohen Alters, das die Inschrift dann hätte, ausgesprochen unwahrscheinlich; vgl. Sauer Olshausen 2018 zu mit der städtischen Ära datierten Inschriften aus Neoklaudiopolis.

${ }^{45} \mathrm{Zu}$ denken ist insbesondere an Paula/Paulus oder Paulina/Paulinos, an Gaius und an Sextia oder Sextiane/Sextianus.

${ }^{46}$ Vgl. diese Wendung in Studia Pontica III 37; 44a; 45; Marek - Adak 2016, 76f. Nr. 82 = SEG 66, 1543; Sauer - Olshausen 2018, 127f. Nr. 2; 132f. Nr. 5; Sauer - Olshausen 2020, 148f. Nr. 4 und ähnlich Studia Pontica III 34a; Olshausen 1987, 86f. Nr. 4 (vgl. Sauer - Olshausen 2018, 125 mit Anm. 5 zum Fundort); Marek 2000, 137-146 Nr. III; außerdem Studia Pontica III 17a und 19b-d, deren Fundorte sehr wahrscheinlich ebenfalls im Territorium von Neoklaudiopolis liegen (vgl. Dalaison - Delrieux 2014, 164f.).
} 
(Z. 5, zweiter Buchstabe) V-förmig. Omega: $\omega$-förmig, dabei einbogig (ähnlich einem liegenden lunaren Epsilon).
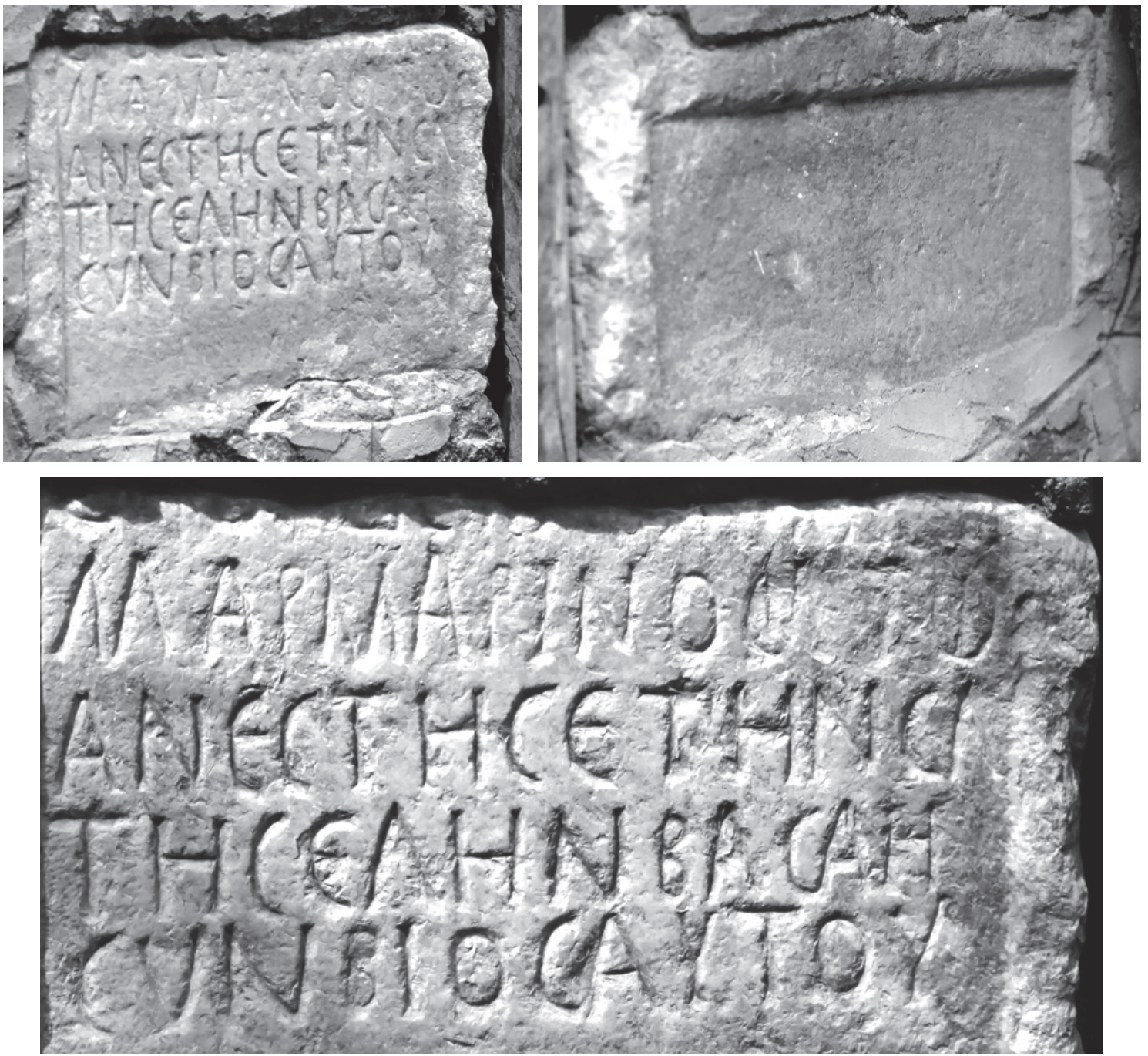

Abb. 22-24) Nr. 12 Gestiftet von Basa

????:?????????

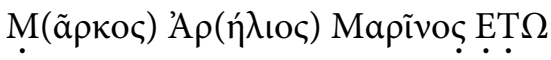

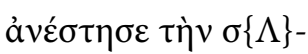

$\tau \eta \dot{\{}\{\Sigma E\} \lambda \eta v$ Bá $\sigma \alpha \dot{\eta}^{v}$

$5 \sigma u ́ v \beta เ о \varsigma$ aủंo $\tilde{v}^{1 / 2 v}$
... Marcus Aurelius

Marinus ... Basa, seine

Lebensgefährtin, hat

die Stele aufgestellt.

vacat - 1-2 Zeilen auf Fragment (a) + 4 Zeilen auf Fragment (b) -

Z. 1 Reste des unteren Abschlusses mehrerer Buchstaben erkennbar. Bei dem wohl fünften handelt es sich um ein Delta. Der erste, der dritte, der wohl sechste und der wohl letzte sind unten bogenförmig gestaltet, wobei es sich beim dritten wohl um Omikron oder Theta, bei den anderen um Sigma oder Epsilon handelt. Außerdem sind an einigen Stellen die unteren Enden von senkrecht oder schräg gestellten Hasten erkennbar. Insgesamt wäre es mit diesen Resten vereinbar,

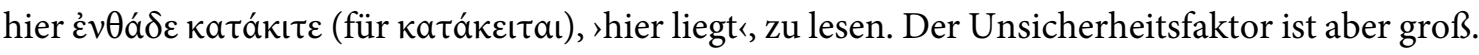




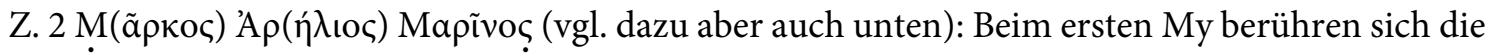
beiden das My bildenden `Lambda< nicht; das Sigma ist annähernd sicher. Bei der oberen Hälfte einer Haste, die man auf dem Photo zwischen dem Sigma und dem folgenden Epsilon zu erkennen vermeint, handelt es sich höchst wahrscheinlich um eine Beschädigung des Steins. ET $\Omega$ : Vom Epsilon zeichnen sich die Arme schemenhaft ab - am Stein und im Abklatsch deutlicher als auf dem Photo. Tau annähernd sicher. Zu überlegen ist, ob hier an eine Altersangabe zu denken ist: $\dot{\varepsilon} \tau \tilde{\omega} \nu \lambda^{\prime}$, wobei das Ny vergessen wurde - auf dem Rand, der hier allerdings etwas bestoßen ist, war es wohl nicht untergebracht -, und das Lambda in die nächste Zeile verrutscht ist (vgl. dazu unten).

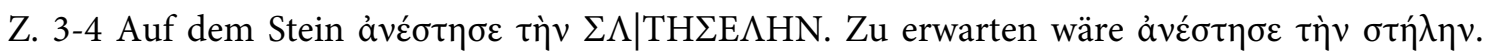
Möglicherweise ist der Steinmetz beim Übertragen des Texts von einer Vorlage in der Zeile verrutscht. Die Buchstabenfolge TH $\Sigma$ E könnte jedenfalls eine Wiederholung derselben Buchstaben-

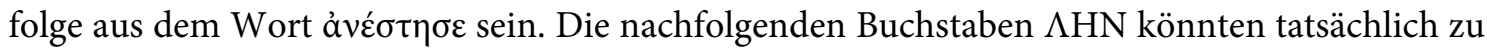
$\sigma \tau \eta ́ \lambda \eta v$ gehören. Das Lambda am Ende von Z. 3 bleibt freilich ohne Erklärung - es sei denn, man nimmt zu der oben zu Z. 2 vorgeschlagenen Überlegung Zuflucht.

Z. 4 Báoa: Der Querstrich des Alpha ist nicht sicher erkennbar.

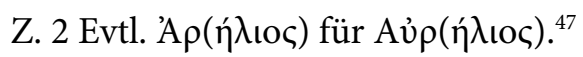

Die Buchstabenfolge MAPMAPINO $\Sigma$ dürfte als Personenname aufzufassen sein. Der Name

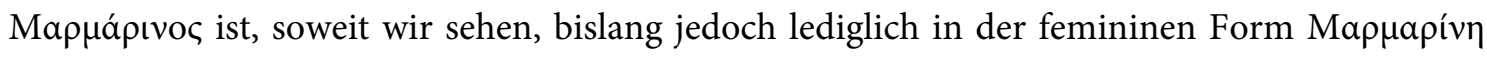

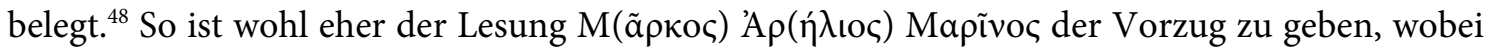

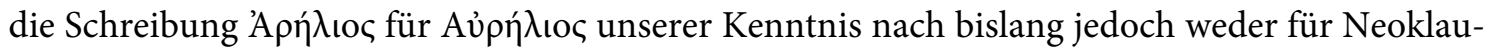
diopolis noch für die Nachbarstädte belegt ist.

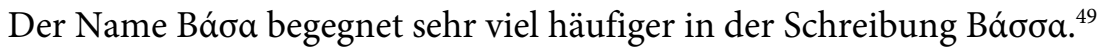

Möglicherweise sollte der Text tatsächlich mit der Nennung der Stifterin der Stele enden. Angesichts des freien Platzes im Schriftfeld ist es aber auch vorstellbar, daß der Steinmetz, nachdem er seine Schreibfehler bemerkt hatte, die Fortsetzung des Textes nicht mehr übertragen und das Werkstück verworfen hat.

\section{Nr. 13 Für Stratonikē}

Pazarc1/Vezirköprü (8,7km südsüdöstl. Veziröprü). Im Haus des Mehmet Yaman links der Türschwelle vermauert. 1989 (Photos, Abklatsch, Skizze der Stele, Abschrift).

Fragment einer Giebelstele. Kalkstein. Giebel- und Schriftfeld vertieft, jeweils von profiliertem Rahmen umgeben. Im Giebelfeld Kranz mit vermutlich drei die Zwickel des Feldes füllenden

\footnotetext{
${ }^{47}$ Vgl. Brixhe 2010, 233f. zu den phonetischen Hintergründen.

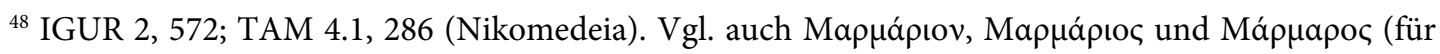
Nachweise vgl. LGPN I und V.A und Marek 2013, 184 Anm. 39).

${ }^{49}$ Für Nachweise vgl. LGPN IV bzw. I, II, III.A, IV, V.A und B.
} 
großen Blättern (nur links und rechts erhalten). ${ }^{50}$ Giebelspitze abgeschlagen, Akrotere bestoßen. Unten gebrochen. Im Bereich der Z. 4-6 vom Erdreich verfärbt.

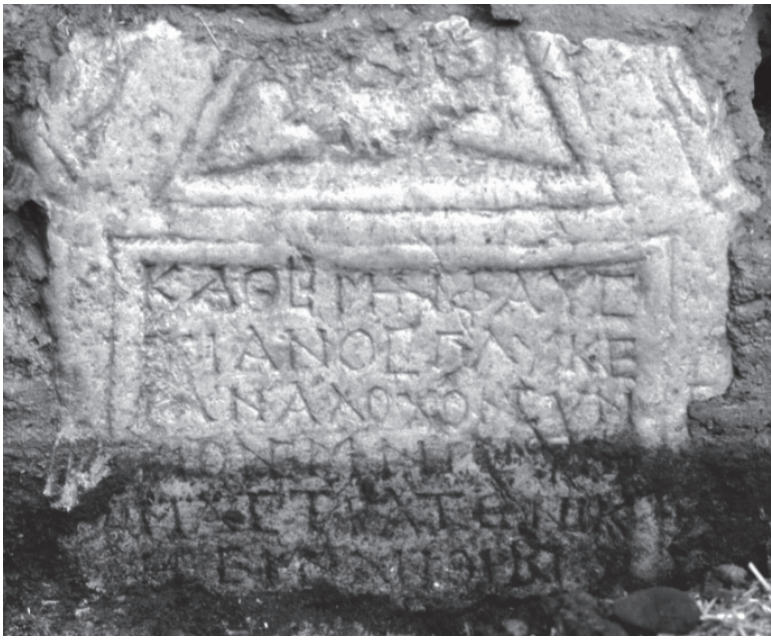

Abb. 25) Nr. 13 Für Stratonikē

H $42 \mathrm{~cm}$; B $44 \mathrm{~cm}$. Schriftfeld: H $25 \mathrm{~cm}$ erhalten; B $31 \mathrm{~cm}$. Bh. 2,0-3,0cm; Phi 3,5cm.

In Z. 1 befindet sich das Iota (mit Epsilon in Ligatur verbunden; vgl. unten) auf dem oberen Rahmen, in Z. 3 der letzte Buchstabe auf dem rechten Rahmen. Alpha: Querstrich waagrecht. Epsilon: eckig. Theta: länglich, Querstrich unverbunden. My: eckig mit parallel stehenden Hasten, das innere $>\mathrm{V}<$ leicht geschwungen. Ny: Diagonale kurz. Omikron: länglich. Sigma: eckig. Ypsilon: in Z. 3 annähernd V-förmig. Phi: Haste lang, Körper queroval. Alpha und Lambda mit Apices. Teils leichter Ansatz zu Serifen.

Ligaturen: Z. 1 EI (die Haste des Epsilon ist nach oben verlängert) und MHN. Z. 3 N L. Z. 4 NE und MHN. Z. $6 \mathrm{H} \sum$, MN und HB. Teilweise gehen die Ligaturen dabei über Wortgrenzen hinweg: Z. 3 N S. Z. 4 NE. Z. $6 \mathrm{H}$ ? und HB.

$\kappa a \theta \varepsilon i ́ \mu \eta \nu$ Фavб-

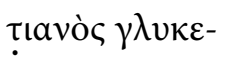

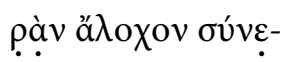

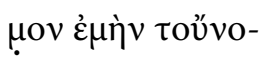

$5 \quad \mu \alpha \Sigma \tau$ โатоvíк-

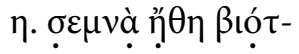

[ov ---]

Ich, Faustianos, habe (meine) süße Gattin, meine Verwandte, namens Stratonikē bestattet. (sc. Ihre) ehrwürdige Lebensart ...

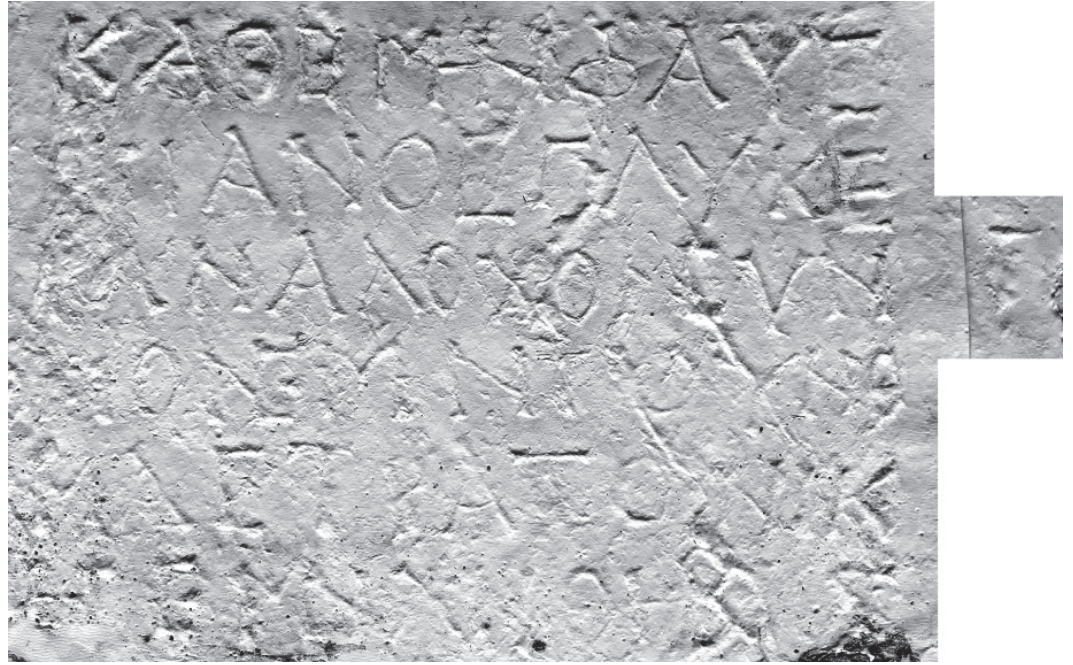

Abb. 26) Nr. 13 Für Stratonike

${ }^{50}$ Größte Ähnlichkeit mit dem Kranz auf der Stele Studia Pontica III 44a (Süleymanköy [vgl. Türkeikarte 1:200.000, Blatt B IX Samsun, Harita Genel Müdürlüğü Ankara 1947: Süleymanköy Mevkii ca. 4km nordnordwestl. İmircik]; 1989 von Eckart Olshausen und Gerhard Kahl in İmircik wiedergesehen); abgesehen von Details der Gestaltung der Blätter auch mit jenem auf der Stele Olshausen 1987, 82f., Nr. 1 (Boğazkoru Köyü; zum Fundort vgl. Sauer - Olshausen 2018, 125 mit Anm. 5); vgl. außerdem Marek - Adak 2016, 81f. Nr. 91 (Ersandık), wobei die Blätter hier aber deutlich kleiner sind. 
Z. 1-2 Фavo| đıavóc: Vom Deckstrich des Tau sind nur die Enden erkennbar, von der Haste nur Spuren.

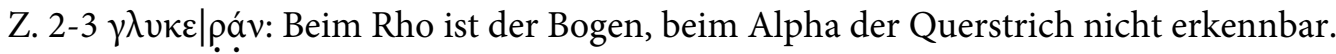

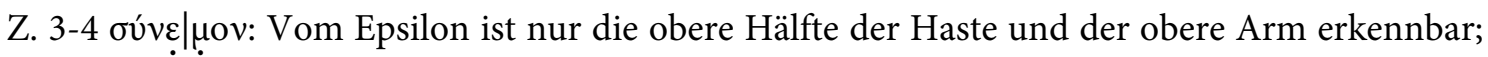
der Rest des Buchstabens ist aber eventuell unter Mörtel vorhanden. Vom My sind nur die Hasten erkennbar.

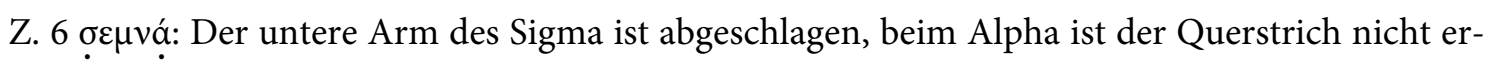
kennbar. ท̆ं $\mid$ : Der Querstrich des Eta zeichnet sich nur schemenhaft ab.

Z. 6-7 ßió $\mid$ |[ov: Das Omikron ist nur schemenhaft erkennbar; das Tau ist - anders als es die Photographie des Abklatsches denken läßt - sicher.

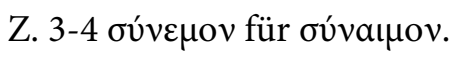

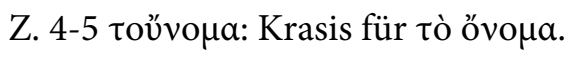

Worttrennung in Z. 5 und 6 nicht syllabisch.

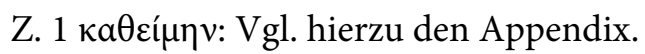

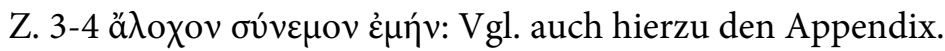

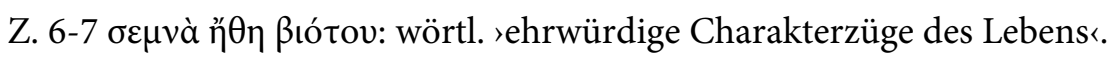

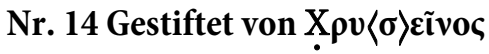

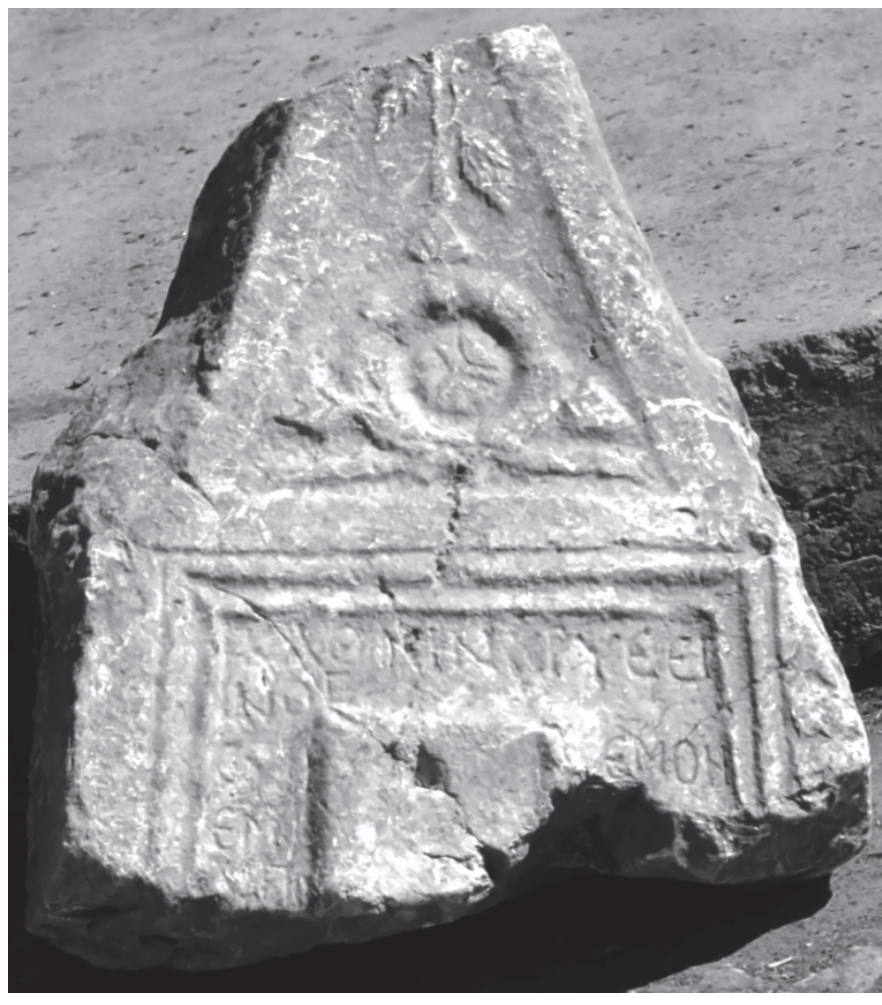

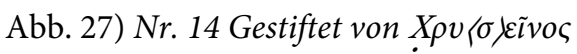

Ilıca/Havza $(10,4 \mathrm{~km}$ nordnordöstl. Havza; 21,6km ostsüdöstl. Vezirköprü). Außerhalb des Ortes abgeladen zur Verwendung im Straßenbau. 1989 (Photos, Abklatsch, Skizze der Stele, Abschrift). Man versicherte, $\mathrm{da} ß$ die Inschrift wieder in den Hof der belediye gebracht werde, und tatsächlich war sie 2013 in einer Grünanlage im Ort aufgestellt. ${ }^{51}$

Fragment einer sich nach oben verjüngenden Giebelstele. Kalkstein. Giebel auffallend spitz. Giebel- und Schriftfeld vertieft. Schriftfeld von profiliertem Rahmen umgeben. Im Giebelfeld Kranz mit Schleife. Aus dem Kranz ragen drei Blätter heraus, die ungefähr auf die Ecken des Feldes zeigen. Auch das Innere des Kranzes war wohl gestaltet. Über dem Kranz

\footnotetext{
${ }^{51}$ Vgl. oben zu Nr. 6.
} 
eine Pflanze. Im Schriftfeld geöffnetes volumen. Giebelspitze abgeschlagen, linker Akroter erheblich bestoßen, der rechte fehlt ganz. Unten gebrochen.

H 80cm; B 65cm; T 45cm. Schriftfeld: H 24cm erhalten; B oben $41 \mathrm{~cm}$. Bh. 3,0-4,0cm.

Z. 2 beginnt in gleichsam normalem Zeilenabstand zur 1. Zeile, der dritte Buchstabe wurde dann aber näher an die 1. Zeile herangerückt, um ihn über dem volumen unterbringen zu können vermutlich in der Absicht, eine nichtsyllabische Trennung innerhalb des Namens des Stifters zu vermeiden; der Rest der Zeile ist freigelassen. Epsilon: lunar. Theta: Querstrich annähernd punktförmig. My: eckig mit parallel stehenden Hasten. Ny: Diagonale teils kurz. Omikron: länglich. Sigma: in Z. 2 eckig, in Z. 3 lunar.

Ligaturen: Z. $1 \Theta \mathrm{E}$ und $\mathrm{HN}$.

$$
\begin{aligned}
& \kappa a \theta \varepsilon \dot{\varepsilon} \mu \eta \nu \text { X } \rho v\langle\sigma\rangle \varepsilon \tilde{l}- \\
& \text { voc }{ }^{\text {vac. }} \\
& \text { бúv volumen } \varepsilon \mu \mathrm{ov} \\
& \dot{\varepsilon} \mu^{1 / 2 y} \text { volumen [ìv ...] } \\
& 5 \quad \Lambda \text { I! volumen }[---]
\end{aligned}
$$

Ich, Chrysinos, habe meine Verwandte bestattet ...

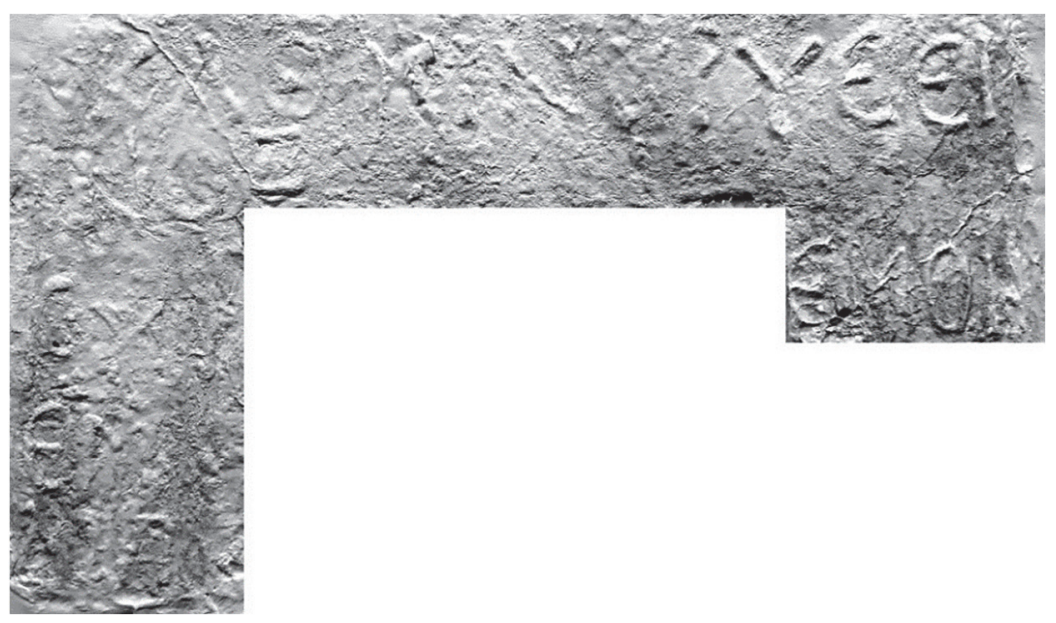

Abb. 28) Nr. 14 Gestiftet von $X \rho v\langle\sigma| \varepsilon i \tilde{v} 0 \varsigma$

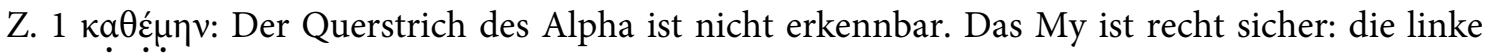

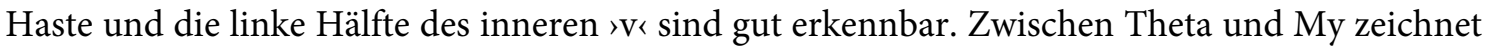
sich schemenhaft eine waagrechte Linie in halber Zeilenhöhe ab, wobei nicht sicher zu sagen ist, ob sie nur das Theta oder auch das My berührt. Da die Lesung кa $\theta \dot{\mu} \mu \eta \nu$ (1. Sgl. Impf. Ind. Med. von $\kappa a \theta \tilde{\eta} \sigma \theta a \mathrm{l})$ wenig plausibel ist, hat die vorgeschlagene wohl etwas mehr für sich - jedenfalls im Licht der Inschriften Marek - Adak 2016, 81f. Nr. 91 und oben Nr. 13 (vgl. dazu auch unten den Appendix).

Z. 1-2 X $\rho v\langle\sigma\rangle \varepsilon i \mid v o \varsigma:$ Auf dem Stein XPYEEI|NOE. Sicherlich der Name des Stifters der Inschrift. Das Chi ist annähernd sicher. Es ist sehr wahrscheinlich, daß dem Steinmetzen beim ersten Epsi-

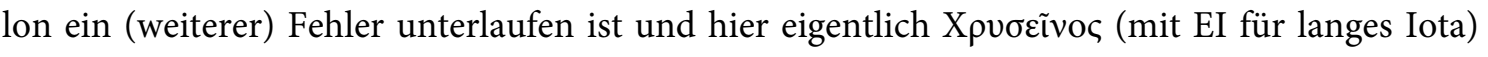
stehen sollte. Allerdings ist dieser Name, soweit wir sehen, bislang in der männlichen Form nur in einer lateinischen Inschrift, und dort auch nicht mit letzter Sicherheit, und in der weiblichen Form Xpvoíva lediglich in einer aus dem 4. Jh. v.Chr. stammenden Inschrift belegt. ${ }^{52}$

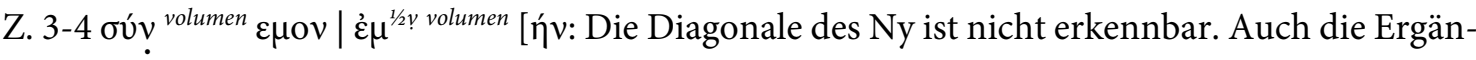
zung $\sigma u ́ v \varepsilon \mu o v \grave{\varepsilon} \mu[o ́ v$ ist grundsätzlich denkbar.

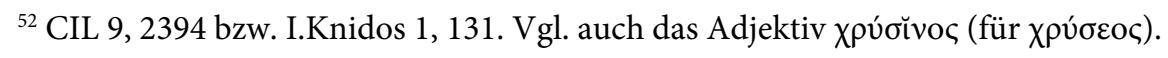


Z. $5 \Lambda$ II!: recht sicher; vielleicht ist an eine Formulierung ähnlich jener in der Inschrift Sauer -

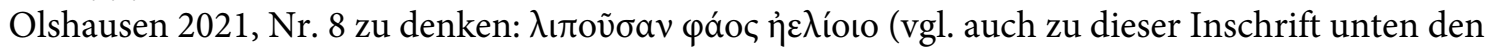
Appendix).

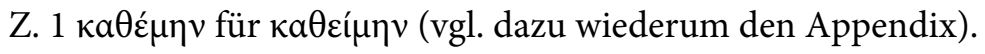

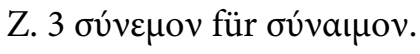

Ohne die Möglichkeit von Steinmetzfehlern überstrapazieren zu wollen, möchten wir zu überlegen geben, ob in der von der Raumaufteilung her etwas verunglückt wirkenden Z. 2 ein Wort ausgefallen ist. Der Vergleich mit den Inschriften Marek - Adak 2016, 81f. Nr. 91 und oben Nr.

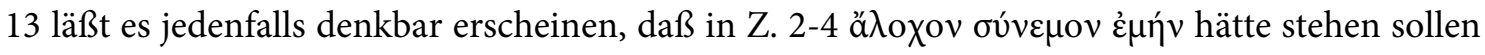
(vgl. auch hierzu den Appendix).

\section{Appendix. Zu einer Inschrift aus Ersandık/Havza \\ (Marek - Adak 2016, 81f. Nr. 91 = SEG 66, 1545)}

Christian Marek erwog, ob in einer von ihm in Ersandık aufgefundenen Inschrift ${ }^{53}$ die Buchsta-

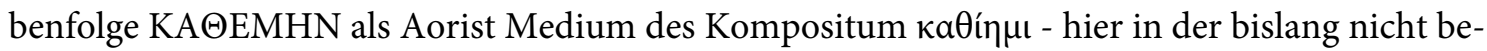
legten Bedeutung `niederlegen`, >unter die Erde bringen ‘ zu erklären sein könnte, und das Fehlen

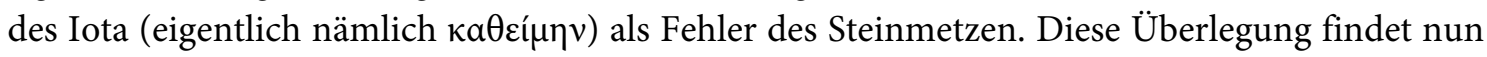
in der oben als Nr. 13 vorgestellten Inschrift aus Pazarcı in gewisser Weise ihre Bestätigung: Diese Inschrift folgt demselben $>$ Formular ${ }^{54}$ und hat dabei zweifellos die Schreibung $\kappa a \theta \varepsilon i ́ \mu \eta v$. Dabei ist jedoch das Iota in Ligatur mit Epsilon verbunden, was für die Inschriften von Neoklaudiopolis höchst ungewöhnlich ist. Da das Iota - in Form der nach oben verlängerten Haste des Epsilon zudem nicht im Schriftfeld, sondern auf dessen oberem Rahmen liegt, ist diese Zeichenverbindung wohl weniger als eine von vornherein geplante Ligatur denn als nachträgliche Korrektur eines Fehlers anzusehen - desselben Fehlers, der sich auch in der Inschrift aus Ersandık und möglicherweise zudem in der oben als Nr. 14 vorgestellten Inschrift aus Ilica und vielleicht auch in einer Inschrift aus Bayram findet: in der Inschrift aus Ilıca, wenn dort tatsächlich, wie vorgeschlagen, $\kappa a \theta \varepsilon\langle i \hat{\rangle} \mu \mu \eta \mathrm{zu}$ lesen ist, in der Inschrift aus Bayram, wenn dort nicht, wie von uns seinerzeit gedach ${ }^{5 \dot{5}}[\kappa \alpha \tau \varepsilon] \theta \varepsilon \dot{\varepsilon} \mu \eta \nu$, sondern $[\kappa \alpha] \theta \varepsilon\langle\hat{i}\rangle \mu \eta \nu$ zu ergänzen sein sollte.

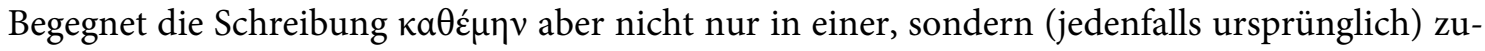
mindest in zwei, wenn nicht gar in drei oder vier Inschriften, ist sie kaum mehr mit einem Lapsus des jeweiligen Steinmetzen erklärbar. Wir möchten daher zu überlegen geben, ob sie nicht vielmehr mit der ortsüblichen Aussprache des Wortes in Verbindung stehen könnte: In manchen Regionen wurden e- und i-Laute zumindest von manchen Personen so ausgesprochen, daß sie verwechselt werden konnten; in der Schreibweise trat folglich hin und wieder I für E und umgekeht E für I (und etwa auch EI) ein. ${ }^{56}$ Auch für Neoklaudiopolis ist I (und auch EI) für E gut belegt, ${ }^{57}$ E für I grundsätzlich bei der Schreibung der Namen Domitia bzw. Domitilla und Domi-

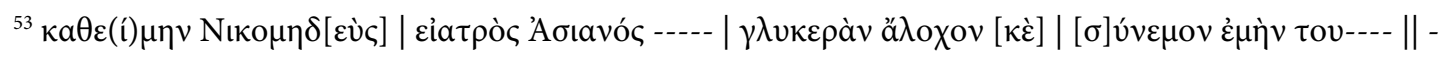
---------- Ersand1k liegt 15,6km westnordwestl. Havza und 12,5km südsüdöstl. Vezirköprü.

${ }^{54}>$ Ich, ..., habe bestattet meine süße Gattin etc.く. Vgl. dazu auch unten.

${ }^{55}$ Sauer - Olshausen 2021, Nr. 8.

${ }^{56}$ Brixhe 1987, 54f; 2010, 233.

${ }^{57}$ Vgl. $\mu \eta \delta$ v́va für $\mu \eta \delta \varepsilon ́ v a$ in Studia Pontica III 38; 44a; 44b; Sauer - Olshausen 2019, 145-147 Nr. 2 , $\mu \eta \delta \varepsilon \tilde{v} v \alpha$ für $\mu \eta \delta \varepsilon ́ v a$ in Sauer - Olshausen 2019, 148-151 Nr. 4 und $\mu \mu \nu \eta \mu \varepsilon ́ v o \varsigma$ für $\mu \varepsilon \mu \nu \eta \mu \varepsilon ́ v o \varsigma$ in Studia
} 


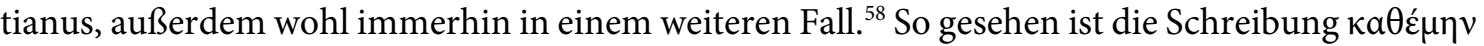

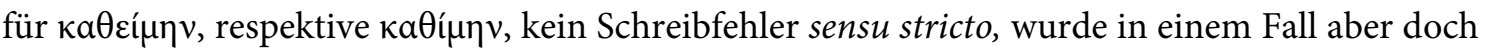
als störend empfunden und korrigiert.

Die hier diskutierten Inschriftentexte haben weitere Gemeinsamkeiten. Besonders auffallend ist, daß

- zumindest in den Inschriften aus Pazarcı, Ersandık und Bayram die Bezeichnung ä $\lambda$ oxoৎ verwandt wird, ${ }^{59}$

- in den Inschriften aus Pazarcı, Ersandık und Ilıca die Bezeichnung oúvaıю verwandt

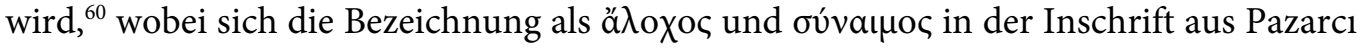
mit Sicherheit auf ein und dieselbe Person bezieht, im Fall der Inschrift aus Ersandık dies zumindest nicht ausgeschlossen ist, ${ }^{61}$ und dies - sollte in der Inschrift aus Ilica der Begriff

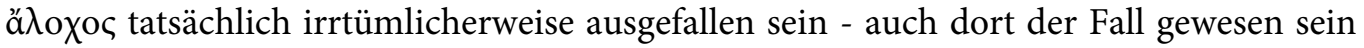
dürfte,

- in den Inschriften aus Pazarcı und Bayram der Name der Verstorbenen ihrer Bezeich-

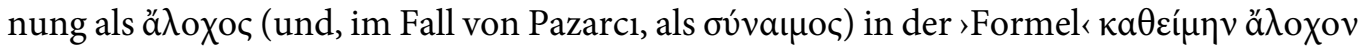

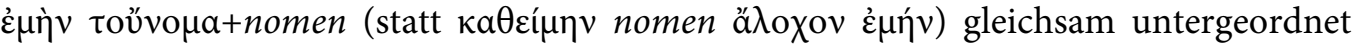
wird, und nicht ausgeschlossen ist, daß dies auch in der Inschriften aus Ilıca so war, während dies im Fall der Inschrift aus Ersandık sogar recht wahrscheinlich ist, ${ }^{62}$

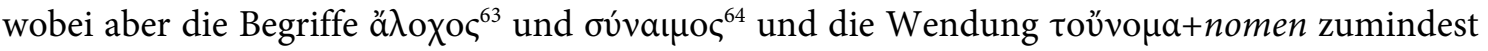
bislang, außer in den hier erwähnten Inschriften, für Neoklaudiopolis nicht belegt sind.

Zumal die Fundorte Pazarc1, Ersandık und Bayram nicht mehr als 5,6km voneinander entfernt sind - Ilıca liegt freilich gut $11 \mathrm{~km}$ östlich dieses $>$ Dreiecks $<$-, ist es angesichts dieser Gemeinsamkeiten, die gleichzeitig Besonderheiten darstellen, sehr wahrscheinlich, daß die Texte dieser vier

Pontica III 20 (in der Notation von Grégoire $\mu \varepsilon] \mu v \eta \mu \varepsilon ́ v o \varsigma$, am Stein - Samsun Arkeoloji ve Etnografya Müzesi Inv.-Nr. 2-7/1970 - und auch in der Umzeichnung von Grégoire ist das Iota aber eindeutig erkennbar und auch vom My sind Teile der rechten Haste erhalten).

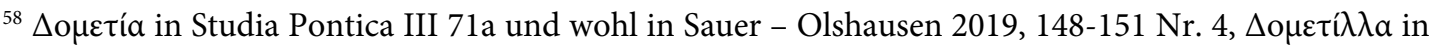

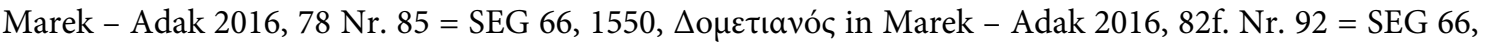

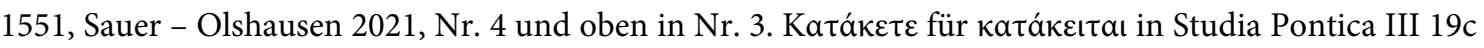

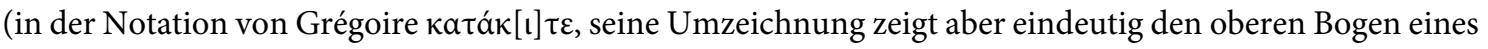
lunaren Epsilon; zum Fundort vgl. oben Anm. 46).

${ }^{59}$ In der Inschrift aus Ilıca ist der Begriff möglicherweise irrtümlich ausgefallen (vgl. dazu oben zu Nr. $14)$.

${ }^{60}$ In der fast vollständig erhaltenen Inschrift aus Bayram war dies definitiv nicht der Fall.

${ }^{61}$ Vgl. dazu auch unten.

${ }^{62} \mathrm{Vgl}$. dazu wiederum unten.

${ }^{63}$ Vgl. zu diesem Begriff auch Sauer - Olshausen 2021, zu Nr. 8.

${ }^{64}$ Ebenso dessen diverse Spielarten wie etwa ö $\mu a \mu$ oc. Vgl. aber Herrmann 1992, 73 zu der grundsätzlichen Beliebtheit dieser Begriffe zur Bezeichnung von Geschwistern insbesondere in Grabepigrammen. 
Inschriften in einer gewissen Abhängigkeit voneinander entstanden sind - worin genau diese auch bestanden haben mag. ${ }^{65}$

Vor diesem Hintergrund ist es u.E. recht wahrscheinlich, daß in der Inschrift aus Ersandık in Z.

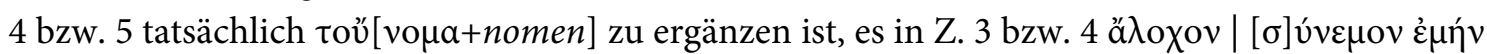
heißt - ohne verbindendes $\kappa \varepsilon ́$ am Ende der 3. Zeile und die Inschrift insgesamt also folgendermaßen zu lesen ist:

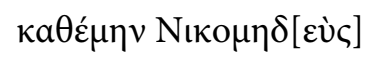

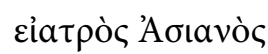

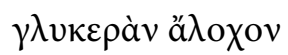

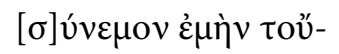

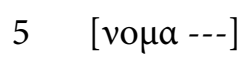

Etwas unbefriedigend ist zugegebenermaßen, daß bei dieser Lesung die erste Zeile rechts um zwei oder drei Buchstaben zumindest über die Zeilen 2 und 3 hinausragt und man annehmen muß, daß entweder die Inschrift rechts nicht bündig gestaltet war oder aber in Z. 1 einige Buchstaben auf dem Rand untergebracht waren. ${ }^{66}$

Offen bleibt, in welchem Verwandtschaftsverhältnis genau die Stifter der Inschriften aus Pazarc1 und Ersandık, gegebenenfalls auch der Stifter der Inschrift aus Ilıca zu ihren Frauen standen. Sehr wahrscheinlich handelte es sich aber um ausgesprochen enge (Bluts-)Verwandte, etwa Cousin und Cousine oder gar Bruder und Schwester. ${ }^{67}$ Deutlich wird hingegen, daß die Stifter der Inschriften es für angezeigt, ja sogar für prestigeträchtig hielten, die Verwandtschaft ausdrücklich zu erwähnen. Dies ist nicht zuletzt insofern bemerkenswert, als für den Norden Kleinasiens in römischer Zeit Ehen zwischen nah verwandten Personen bislang nur ganz vereinzelt eindeutig bezeugt sind. ${ }^{68}$

${ }^{65}$ Die Gestaltung der Stelen insgesamt weist bei manchen Ähnlichkeiten doch auch deutliche Unterschiede auf, so daß man sie wohl kaum mit Sicherheit ein und derselben Werkstatt zuweisen wird.

${ }^{66}$ Davon, daß die Herkunftsangabe als Nıко $\mu \eta \delta(\varepsilon v ́ \varsigma)$ abgekürzt war, wird man wohl kaum ausgehen wollen. - Gleichsam in einem Postscriptum sei erwähnt, daß Elias Sverkos jüngst erwogen hat, NIKOMH $\Delta$

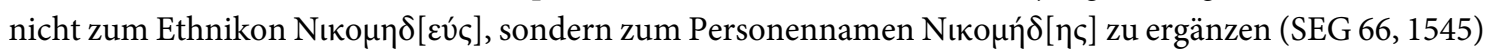
- eine Möglichkeit, auf die freundlicherweise auch unser/-e anonyme/-r Gutacher/-in hingewiesen hat.

${ }^{67} \mathrm{Zu}$ Ehen zwischen eng Verwandten im römischen Kleinasien vgl. insbesondere Thonemann 2017; Beispiele von Geschwisterehen auch bei Marek 2010, 573 mit Anm. 201 auf S. 732.

${ }^{68}$ So für ein Paar aus Amastris (Marek 1993, 164 Nr. 22; Cousin/Cousine), außerdem für eines aus Pompeiopolis (Durugönül 1993 = SEG 43, 925; vgl. auch Marek 1993, 150 Nr. 51 Taf. 43,3; Bruder/Schwester), wenn man der Interpretation der Ikonographie durch Serra Durugönül folgt. 


\section{Bibliographie}

Adak - Akyürek Şahin 2005

Bekker-Nielsen - Høgel 2012

Bekker-Nielsen - Høgel Sørensen 2015
M. Adak - N. E. Akyürek Şahin, Katalog der Inschriften im Museum von Adapazarı, Gephyra 2, 2005, 133-172.

T. Bekker-Nielsen - C. Høgel, Three Epitaphs from the Vezirköprü Region, EpigrAnat 45, 2012, 153-160. 115-136.

Blass - Debrunner - Reh- F. Blass - A. Debrunner, Grammatik des neutestamentlichen Griekopf 2001 chisch. Bearbeitet von F. Rehkopf, 18. Aufl. Göttingen 2001.

Brixhe 1987 C. Brixhe, Essai sur le grec anatolien au début de notre ère, 2. Aufl., Nancy 1987 (Traveaux et mémoires: études anciennes 1).

Brixhe 2010

C. Brixhe, Linguistic Diversity in Asia Minor during the Empire: Koine and Non-Greek Languages, in: E. J. Bakker (Hg.), A Companion to the Ancient Greek Language, Chichester u.a. 2010, 228-252.

Camodeca 2002

G. Camodeca, I consoli del 43 e gli Antistii Veteres d'età claudia dalla riedizione delle Tabulae Herculanenses, ZPE 140, 2002, 227-236.

Dalaison - Delrieux 2014 J. Dalaison - F. Delrieux, La cité de Néapolis-Néoclaudiopolis: histoire et pratiques monétaires, Anatolia Antiqua 22, 2014, 159-198.

De Rossi 1979

Durugönül 1993

G. M. De Rossi, Bovillae, Firenze 1979 (Forma Italiae, Regio I, vol. 15).

S. Durugönül, A $\triangle \mathrm{E} \Lambda \Phi \mathrm{O} \Sigma \mathrm{KAI}$ A $\triangle \mathrm{E} \Lambda \Phi H$. Grabstele eines Geschwister-Ehepaares aus Pompeiupolis in Paphlagonien, EpigrAnat 21, 1993, 61-69, Taf. 8.

Gignac 1976

F. T. Gignac, A Grammar of the Greek Papyri of the Roman and Byzantine Periods. Vol. I: Phonology, Milano 1976 (Testi e documenti per lo studio dell' antichità 55).

I.Gaza

C. A. M. Glucker, The City of Gaza in the Roman and Byzantine periods. Appendix: The Inscriptions of Gaza, pp. 115-163, Oxford 1987 (BAR International series 325).

Haensch 1993

R. Haensch, Ein Procurator der Provinz Arabia und die angeblichen Beinamen Aurelia Antoniniana von Gerasa, ZPE 95, 1993, 163-178, Taf. III.

Harter-Uibopuu 2013

K. Harter-Uibopuu, IG XIV 943 - eine metrische Strafklausel aus Portus, in: P. Mauritsch, C. Ulf (Hg.), Kultur(en) - Formen des Alltäglichen in der Antike. FS für Ingomar Weiler zum 75. Geburtstag, Graz 2013 (Nummi et Litterae 7), 177-191.

Herrmann 1992

P. Herrmann, Epigraphische Notizen 4-9, EpigrAnat 20, 1992, 69-74.

Herrmann-Otto 1994

E. Herrmann-Otto, Ex ancilla natus. Untersuchungen zu den »hausgeborenen « Sklaven und Sklavinnen im Westen des Römischen Kaiserreiches, Stuttgart 1994 (Forschungen zur antiken Sklaverei 24). 
Herrmann-Otto 2012

Herrmann-Otto 2017

Horsley 1992

ICG

Kahl 1995

Kahl - Olshausen 1991

Kajanto 1963

Kajanto 1965

LMentana

Madsen 2009

Marek 1993

Marek 2000

Marek 2003

Marek 2010

Marek 2013

Marek - Adak 2016

McLean 2002
E. Herrmann-Otto, Kindsein im Römischen Reich, in: H. Heinen (Hg.), Kindersklaven - Sklavenkinder, Schicksale zwischen Zuneigung und Ausbeutung in der Antike und im interkulturellen Vergleich, Stuttgart 2012 (Forschungen zur antiken Sklaverei 39), 171201.

E. Herrmann-Otto, Sklaverei und Freilassung in der griechisch-römischen Welt, Hildesheim u.a., 2. Aufl. 2017 (Studienbücher Antike 15).

G. H. R. Horsley, Names, Double, in: The Anchor Bible Dictionary 4, 2. Aufl. 1992, 1011-1017.

C. Breytenbach, C. Zimmermann (Hg.), Inscriptiones Christianae Graecae. A Digital Collection of Greek Early Christian Inscriptions from Asia Minor and Greece (http://www.epigraph.topoi.org).

G. Kahl, Pontica I, OTerr 1, 1995, 109-119, Taf. 9.

G. Kahl - E. Olshausen, Bericht über die epigraphische und numismatische Landesaufnahme im Samsun İli 1990, AST 9, 611-616.

I. Kajanto, Onomastic studies in the early christian inscriptions of Rome and Carthage, Helsinki 1963 (Acta Instituti Romani Finlandiae 2.1).

I. Kajanto, The Latin Cognomina, Helsinki 1965 (Commentationes Humanarum Litterarum 36.2).

G. Barbieri (Hg.), Il Lapidario Zeri di Mentana, 2 Bd., Rom 1982 [non vidimus].

J. M. Madsen, Eager to be Roman. Greek Response to Roman Rule in Pontus and Bithynia, London 2009.

C. Marek, Stadt, Ära und Territorium in Pontus-Bithynia und NordGalatia, Tübingen 1993 (Istanbuler Forschungen 39).

C. Marek, Der höchste, beste, größte, allmächtige Gott. Inschriften aus Nordkleinasien, EpigrAnat 32, 2000, 129-146.

C. Marek, Pontus et Bithynia. Die römischen Provinzen im Norden Kleinasiens, Mainz 2003 (Orbis provinciarum. Sonderbände der Antiken Welt. Zaberns Bildbände zur Archäologie).

C. Marek, Geschichte Kleinasiens in der Antike. Unter Mitarbeit von Peter Frei, München, 2. Aufl. 2010.

C. Marek, Imperial Asia Minor: Economic Prosperity and Names, in:

R. Parker (Hg.), Personal Names in Ancient Anatolia, Oxford 2013 (PBA 191), 175-194.

C. Marek - M. Adak, Epigraphische Forschungen in Bithynien, Paphlagonien, Galatien und Pontos, İstanbul 2016 (Philia Supplements 2).

B. H. McLean, An introduction to Greek epigraphy of the Hellenistic and Roman periods from Alexander the Great down to the reign of Constantine (323 B.C.-A.D. 337), Ann Arbor 2002. 
Olshausen 1987

Olshausen 1990

Olshausen - Biller 1984

Öztürk 2013

Peek 1942

Robert 1938

Sauer - Olshausen 2018

Sauer - Olshausen 2019

Sauer - Olshausen 2020

Sauer - Olshausen 2021

Schulze 1904

Schwyzer 1939/1950

Solin - Salomies 1994

Sørensen 2013
E. Olshausen, Griechische Grabinschriften der Kaiserzeit im Museum von Samsun, EpigrAnat 9, 1987, 81-95, Taf. 7-10.

E. Olshausen, Bericht über die epigraphische Landesaufnahme im Samsun İli 1989, AST 8, 1990, 247-249.

E. Olshausen - J. Biller, Historisch-geographische Aspekte der Geschichte des Pontischen und Armenischen Reiches. Teil 1: Untersuchungen zur historischen Geographie von Pontos unter den Mithradatiden, Wiesbaden 1984 (Beihefte zum Tübinger Atlas des Vorderen Orients, Reihe B, 29/1).

H. S. Öztürk, Nikaia'dan Yeni Yazıtlar IV: İznik Arkeoloji Müzesi (Bursa). New inscriptions from Nicaea IV: Iznik Archaeological Museum (Bursa), Cedrus 1, 2013, 293-298.

W. Peek, Attische Inschriften. Nachträge und Verbesserungen zu IG. $I^{2}$. II ${ }^{2}, \operatorname{MDAI}(A)$ 67, 1942, 1-217, Taf. 1-23.

L. Robert, Études épigraphiques et philologiques, Paris 1938 (Bibliothèque de l'École des Hautes Études 272).

V. Sauer - E. Olshausen, Mit der städtischen Ära datierte Inschriften aus Neoklaudiopolis (Vezirköprü/Samsun İli, Türkei), EpigrAnat 51, 2018, 125-145.

V. Sauer - E. Olshausen, Grabflüche aus Neoklaudiopolis (Vezirköprü/Samsun İli, Türkei), EpigrAnat 52, 2019, 143-166.

V. Sauer - E. Olshausen, Die Tätigkeit in Landwirtschaft und Staat als Tugend. Grabinschriften aus Neoklaudiopolis (Vezirköprü/Samsun İli, Türkei), EpigrAnat 53, 2020, 141-162.

V. Sauer - E. Olshausen, Schutz durch Strafandrohung. Grabinschriften aus Neoklaudiopolis (Vezirköprü/Samsun İli, Türkei), EpigrAnat 54, 2021 (im Druck).

W. Schulze, Zur Geschichte lateinischer Eigennamen, Berlin 1904 (Abhandlungen der Akademie der Königlichen Gesellschaft der Wissenschaften zu Göttingen. Philologisch-Historische Klasse. Neue Folge 5.5).

E. Schwyzer, Griechische Grammatik. Bd. 1: Allgemeiner Teil. Lautlehre, Wortbildung, Flexion; Bd. 2: Syntax und syntaktische Stilistik (vervollständigt und herausgegeben von Albert Debrunner), München 1939/1950 (Handbuch der Altertumswissenschaft II.1.1 und 2).

H. Solin - O. Salomies, Repertorium nominum gentilium et cognominum Latinorum, Hildesheim u.a. Editio nova, addendis corrigendisque augmentata, 1994 (Alpha-Omega. Reihe A, Lexika, Indizes, Konkordanzen zur klassischen Philologie 80).

S. L. Sørensen, Imperial Priests in Neoklaudiopolis, EpigrAnat 46, 2013, 176-180. 
Staab 2018

Temür - Yiğitpaşa 2020

Thonemann 2017

Waelkens 1986

Wheeler 2012
G. Staab, Gebrochener Glanz. Klassische Tradition und Alltagswelt im Spiegel neuer und alter Grabepigramme des griechischen Ostens, Berlin, Boston 2018 (Untersuchungen zur antiken Literatur und Geschichte 130).

A. Temür - D. Yiğitpaşa, Neoklaudiopolis Antik Kenti ve Territoryumu 2019 Yüzey Araştırması ve Envanter Çalışmaları. Neoklaudiopolis Ancient City and Territory 2019 Surveys and Inventory Studies, in: History Studies 12.6, 2020, 2867-2894.

P. Thonemann, Close-kin marriage in Roman Anatolia, CCJ 63, 2017, 143-166.

M. Waelkens, Die kleinasiatischen Türsteine. Typologie und epigraphische Untersuchungen der kleinasiatischen Grabreliefs mit Scheintür, Mainz 1986.

E. L. Wheeler, Roman fleets in the Black Sea: Mysteries of the Classis Pontica, in: AClass 55, 2012, 119-154.

\section{Neoklaudiopolis’ten Yeni Mezar Yazıtları (Vezirköprü/Samsun) \\ Özet}

Günümüze kadar Neoklaudiopolis/Vezirköprü egemenlik alanından 140 kadar mezar yazıtı bilinmektedir. Bu makalede, bir tanesi belki Amaseia/Amasya'dan olmak üzere (no. 4), 14 tane daha yeni yazıt yayımlanmaktadır. Bu yazıtlar 1988 ve 1990 yılları arasında Eckart Olshausen ve Gerhard Kahl tarafından kaydedilmiştir. Yazıtların hepsi Roma İmparatorluk Dönemi’ne tarihlenmektedir.

Stellerden bir tanesi nadir görülen üst düzey taş işçiliğiyle kendini göstermektedir (no. 8); bu stel bir emekli subay tarafından eşi için dikilmiştir. Diğer üç stel ya Neoklaudiopolis için olağan olmayan bir şekilde yapılmıştır ya da kentin egemenlik alanında bulunan stellerde henüz görülmeyen dekoratif öğeleri içermektedir: 1 ve 2 numaralı eserlerde birbirleriyle bir silme ile ayrılan alınlık ve yazıt alanı arasına betimsel alan yerleştirilmiştir. 4 numaralı eserde yazıtın üzerinde bir çelenk bulunmaktadır.

İki yazıtta (no. 4 ve 9) ölçülü bir dil kullanmıştır. Bazıları nadiren görülen kişi isimleri içermektedir (no. 1, 2, 7, 9 ve 14, olasılıkla no. 12). En az iki yazıtta yaş bilgisi bulunmaktadır (no. 10-11 ve olasılıkla no. 12). 2 ve 13 numaralı yazıtlar özellikle içerik bakımından ilginçtir. No. 2'de bir adam ve annesinin akıbeti yansıtılmaktadır. No. 13te steli diken kişi ölmüş karısını açık bir şekilde akrabası olarak göstermiştir.

Son olarak, 13 ve 14 numaralı yazıtların ışığında, Christian Marek tarafından yayımlanmış bir yazıt ek bölümde tartışılmaktadır

Yazıtların Türkçe çevirileri şöyledir:

No. 1: Usius Harpastos pek kıymetli eşi Usia Eutykhis için anısı vesilesiyle (yaptırdı).

No. 2: Ben, Usius Eleutheros (bu steli) dört yaşındayken beni uzağa yollayan kendi annemin anısı vesilesiyle diktirdim.

No. 3: Kyrilla bu steli saygıdeğer ve kusursuz bir şekilde yaşamın sürmüş olan pek tatl eşi Dometianus'a, mezarının üzerine ebedi anısı için diktirdi ... 
No. 4: Erken ölen ... aşă̆ıda, toprağın gizemli derinliklerinde ...

No. 5: Kloipatra kocası Phelikion için, değerbilirliği vesilesiyle diktirdi.

No. 6: Dionysis kendi karısı Antiokhidis için, anısı vesilesiyle (diktirdi).

No. 7: Candidus ve Aspasia, bu mezar taşını kendi oğulları Iustus Vespasianus için (yaptırdı).

No. 8: Emekli subay Aurelius Carus kendisiyle birlikte yaşam sürmüş olan karısı Hostilia Kyriake'yi ... (onurlandird $)$.

No. 10: Biz, [Antonius] Iustus ve Antonia Tertulla (bu steli) kızımız Antonia için anısı vesilesiyle diktirdik. 6 yaşındayken öldü.

No. 12: ... Marcus Aurelius Marinus ... bu steli diktirdi ... eşi Basa.

No. 13: Ben, Faustinos, akrabam olan Stratonike isimli tatl eşimi gömdüm. Saygıdeğer bir yaşam ...

No. 14: Ben, Khryseinos, akrabam .... gömdüm.

Anahtar sözcükler: Neoklaudiopolis/Vezirköprü, Yunan epigrafisi, mezar yazıtları, alınlıklı steller, azatlılar, emekli subay, eusebeia, yakın akraba evliliği.

\section{New Funerary Inscriptions from Neoklaudiopolis (Vezirköprü/Samsun İli, Turkey)}

\section{Abstract}

Up to now, about 140 funerary inscriptions were known from the territory of Neoklaudiopolis/ Vezirköprü. In this contribution, 14 more are presented, one of which, however, may be attributed to Amaseia/Amasya (no. 4). They were recorded between 1988 and 1990 by Eckart Olshausen and Gerhard Kahl. All of them date back to the Roman Imperial period.

One of the stelae stands out for its unusually high-quality stone carving (no. 8); it was erected by a veteran for his wife. Three other stelae are either composed in a way unusual for Neoklaudiopolis or contain decorative elements, which, until now, are not attested for grave stelae from the territory of this polis: at nos. 1 and 2 a depictive field was inserted between the pediment and the inscription field being separated from the latter by a moulding, at no. 4 a garland is placed above the inscription.

Two of the inscriptions use metric language (nos. 4 and 9). Some of them contain rarely attested personal names (nos. 1, 2, 7, 9 and 14, possibly also in no. 12). Age information is found in at least two (nos. 10 and 11, possibly also in no. 12). No. 2 and no. 13 are particularly interesting in terms of content. No. 2 mirrors the fate of a man and his mother. In no. 13, the donor of the stele explicitly refers to his deceased wife as his relative.

Finally, in the light of inscriptions nos. 13 and 14, we discuss an inscription published by Christian Marek in an appendix.

Keywords: Neoklaudiopolis/Vezirköprü, Greek epigraphy, funerary inscriptions, pediment stelae, freedmen, veteran; eusebeia, close-kin marriage. 